\title{
Análise paramétrica de iluminação natural e de proteção solar de edifícios torcidos
}

\author{
Parametric analysis of natural lighting and sun protection \\ in twisted buildings
}

\section{Camila Leone \\ Wilson Florio}

\section{Resumo}

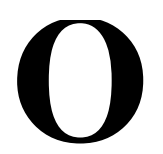

presente artigo tem como objetivo analisar como a modelagem paramétrica (MP) e as simulações computacionais podem auxiliar na avaliação do desempenho da iluminação natural e da insolação de edifícios não ortogonais durante o processo de projeto. Com o propósito de comparar diferentes percentuais de transparência das janelas da fachada, assim como de diferentes tipos de proteção solar para avaliação da iluminação natural no interior de um edificio modelo e a incidência de radiação solar na fachada, foram realizados 6 experimentos no programa Rhinoceros com os plug-ins Grasshopper, Ladybug e Honeybee. O presente estudo centra-se apenas na análise da relação entre o formato das aberturas e das proteções solares sobre o desempenho da iluminação natural e da incidência dos raios solares. Os resultados demonstraram que a torção da edificação não contribui para melhores índices da iluminação natural no seu interior, fazendo com que determinadas áreas da fachada ficassem mais expostas à radiação solar, enquanto outras áreas fossem mais protegidas devido ao autossombreamento. A contribuição original deste artigo é a aplicação da modelagem e simulação paramétrica no processo de projeto e como meio de avaliação do desempenho de edifícios torcidos.

Palavras-chave: Modelagem paramétrica. Radiação solar. Iluminação natural. Projeto baseado em desempenho. Algoritmo.

\begin{abstract}
This paper aims to analyse how parametric modelling (PM) and computer simulations can assist in the evaluation of the performance of natural lighting and the insolation of non-orthogonal buildings during the design process. In order to compare different percentages of transparency of the facade windows, as well as different types of sun protection to assess natural lighting inside a model building, and the incidence of solar radiation on the facade, 6 experiments were performed in the Rhinoceros program with the Grasshopper, Ladybug and Honeybee plug-ins. The present study focuses solely on the analysis of the relationship between the shape of the openings and the solar protections on the performance of natural lighting and the incidence of sunlight. The results showed that the building's torsion does not contribute to better levels of natural lighting inside, making certain areas of the facade more exposed to solar radiation, while other areas were more protected due to self-shading. The original contribution of this paper is the application of parametric modelling and simulation in the design process and as a means to evaluate the performance of twisted buildings.
\end{abstract}

Keywords: Parametric modelling. Solar radiation. Natural lighting. Performance-based design. Algorithms.
Recebido em 28/08/20 Aceito em 04/02/21
${ }^{1}$ Camila Leone São Paulo - SP - Brasil

${ }^{2}$ Wilson Florio ¿Universidade Presbiteriana Mackenzie São Paulo - SP - Brasil

mbiente Construído, Porto Alegre, v. 21, n. 4, p. 247-270, out./dez 2021.

ISSN 1678-8621 Associação Nacional de Tecnologia do Ambiente Construído.

http: //dx.doi.org/10.1590/s1678-86212021000400568 


\section{Introdução}

Arquitetos e pesquisadores importantes na atualidade, como Schumacher (2009), Scheurer (2010), Burry (2005) e Carpo (2011), entre outros, têm destacado alterações significativas na prática projetual da arquitetura contemporânea, com propostas de edifícios com geometrias cada vez mais complexas decorrentes, sobretudo da aplicação de tecnologias digitais no processo de projeto.

Segundo Carpo (2011), enquanto a Era Mecânica propiciava a cópia idêntica dos objetos (paradigma dos idênticos), a Era Digital permitiu a variabilidade das formas, na qual a diferenciação é programada e torna-se parte de um processo automatizado. A partir desse contexto, Picon (2010) aborda o conceito de versoning, isto é, a criação de diferentes versões de uma mesma ideia, por meio de manipulação de parâmetros. Nesse processo, a estratégia não é definir a forma à priori, e sim encontrar a forma, no processo denominado formfinding (SCHODEK et al., 2004).

À medida que os programas computacionais evoluíram, as avaliações foram facilitadas e permitiram a interpretação de geometrias complexas. Nas duas últimas décadas proliferaram propostas de edifícios altos de geometrias complexas.

A investigação realizada por Karel Vollers (2001) a respeito da geometria de edifícios torcidos, isto é, edifícios cujas superfícies externas apresentam dupla curvatura, com foco na definição de esquadrias, é uma das raras publicações a respeito desse tema.

Mas a concepção arquitetônica está intrinsecamente ligada às condições climáticas, exigindo que as estratégias de projeto contribuam para o melhor desempenho da edificação, e viabilizem maior conforto aos usuários.

Ambientes com iluminação adequada às atividades a serem desenvolvidas e com condições satisfatórias quanto aos aspectos térmicos contribuem para maior percepção de conforto e bem-estar. Segundo Cotta e Vieira (2015), em edifícios corporativos as aberturas na fachada colaboram para a satisfação e rendimento dos funcionários.

No entanto, as envoltórias que apresentam grandes aberturas podem resultar em ambientes com maior ruído devido ao som externo, assim como excesso de ofuscamento e superaquecimento devido à maior incidência dos raios solares (MASCARÓ, 1991). Por outro lado, a iluminação natural de alto desempenho é resultante da capacidade técnica em aproveitá-la para realização de tarefas, beneficiando-se das vantagens da comunicação visual com o meio externo e sem o impacto do superaquecimento e do ofuscamento (GONÇALVES; BAKER, 2015). Elementos de sombreamento dimensionados adequadamente representam soluções de projeto que colaboram para o conforto luminoso, redução de calor advindo da radiação solar e redução do consumo de energia.

Na última década a modelagem paramétrica (MP) tem intensificado soluções variadas, das quais novas formas podem surgir por meio da combinação entre parâmetros de um algoritmo, cujas variações resultam na produção de soluções criativas, diferentes e inesperadas.

Por ser dinâmica, a MP e as simulações decorrentes dos algoritmos possibilitam a proposição de diferentes edifícios. Assim, além de permitir a geração de alternativas de projeto, auxilia as decisões a partir de análises comparativas entre as várias opções geradas de projeto. A utilização conjunta da MP com softwares de simulação computacional melhora o estudo do desempenho da edificação que está sendo proposta, garantindo maior segurança nas decisões e, principalmente, melhor bem-estar do futuro usuário. Esse contexto evidencia a relevância em analisar a iluminação natural e insolação nos edifícios com o auxílio das ferramentas digitais.

Na investigação científica realizada na dissertação de mestrado (LEONE, 2017), foram concebidos modelos de edifício altos (com 60 pavimentos) com formato retilíneo (ortogonal) e torcido (não ortogonal) por meio de modelagem paramétrica e, posteriormente, averiguados digitalmente. Concomitantemente, janelas, cada qual com percentuais de abertura distintos, e proteções solares foram elaboradas e analisadas. O presente artigo demonstra um processo de projeto com objetivo de avaliar a iluminação natural no interior do ambiente e a incidência de radiação na envoltória do edifício. Dessa forma, simulam-se diferentes configurações de aberturas e analisam-se distintas soluções de proteção solar.

Em seguida, os cenários são confrontados com o propósito de comparar os resultados entre a geometria retilínea e curvilínea. Com esse procedimento, a solução mais adequada caracteriza-se por apresentar maior iluminação natural no interior do ambiente e menor incidência da radiação solar na envoltória visando melhores condições de desempenho do edifício e maior conforto aos usuários da edificação. Como resultado, 
são evidenciadas as principais características e contribuições da modelagem paramétrica como recurso computacional para a exploração de diferentes configurações geométricas a partir das variações parametrizadas.

\section{Referencial teórico \\ lluminação natural e radiação solar}

Ambientes dotados de conforto térmico e lumínico dependem de estratégias de projeto que levem em consideração as condições climáticas do contexto específico no qual o edifício será implantado. Sendo assim, tanto o desempenho dos edifícios, quanto a percepção de conforto dependem das variáveis do clima a que ambos estão expostos (DUARTE, 2015).

Em regiões tropicais o conforto em um ambiente está relacionado com a radiação solar, sendo assim, seu controle é a maneira mais eficiente de alcançar um ambiente confortável (EMMANUEL, 1993). Assim, torna-se evidente a importância tanto da forma do edifício como sua orientação solar.

Elementos para proteção solar tornam-se fundamentais para o bom desempenho ambiental de edifícios situados em zonas climáticas tropicais, pois são capazes de reduzir a demanda energética (GONÇALVES; BAKER, 2015). Para utilização da proteção solar deve-se levar em consideração dados da latitude, orientação das fachadas e entorno imediato que possa obstruir a abóboda celeste ou causar sombreamento (FROTA, 2004).

A luz é percebida pelo observador de forma direta ou refletida, podendo ser: luz de sol ou luz de céu. A iluminação natural refere-se ao fator de céu, ou seja, a luz de céu disponível para o lugar a ser estudado, já a insolação condiz ao fator de sol, portanto a radiação solar incidente sobre o projeto (LABORATÓRIO..., 2009).

Proteções solares são consideradas eficazes quando forem capazes de barrar a radiação solar direta sobre uma dada superfície ou abertura no período ou dia do ano que se julgar conveniente (FROTA; SCHIFFER, 2001).

Devido ao aperfeiçoamento tecnológico, tais elementos de proteção podem ser empregados no projeto de arquitetura com maior liberdade, mesmo em edifícios complexos. Assim, o desafio que se impõe refere-se à empregabilidade dos elementos de sombreamento de maneira adequada e eficaz na concepção arquitetônica.

Uma vez que os edifícios têm se tornado cada vez mais complexos, mostra-se imprescindível o domínio técnico e a utilização de ferramentas digitais que possam auxiliar a busca por resultados capazes de conciliar maior eficiência à forma, desempenho, estética, construtibilidade, entre outros fatores.

\section{Modelagem paramétrica e simulação computacional}

Segundo Schodek et al. (2004) a arquitetura complexa não é recente, podendo ser exemplificada pela complexidade espacial presente na arquitetura gótica, como nas obras de Gaudi. No entanto, nas últimas décadas as tecnologias digitais têm possibilitado a proliferação de propostas de edifícios torcidos cada vez mais ousadas, demandando cuidados especiais derivados de sua geometria não usual.

A partir dos anos 2000 o uso da MP alterou o processo de projeto durante a concepção de formas complexas. A inserção de algoritmos para auxiliar a geração de novos edifícios alterou o processo de projeto, gerando novas possibilidades formais, uma vez que a MP permite introduzir e combinar parâmetros, manipular equações matemáticas, e, sobretudo, gerar um conjunto de alternativas para serem avaliadas. Dessa maneira, a grande mudança na estratégia do projeto é a exploração das potencialidades da combinação de parâmetros para gerar formas inesperadas, e, ao mesmo tempo, avaliar o desempenho, e assim propiciar decisões mais bem embasadas.

O conceito de Performance-Based Design refere-se à criação e o desenvolvimento do projeto a partir da avaliação do desempenho (KOLAREVIC, 2003). Simultaneamente, nesse processo a forma é criada e, ao mesmo tempo, avaliada e readequada.

$\mathrm{Na}$ presente pesquisa constatou-se que a busca pela forma (form-finding) resultante da elaboração e utilização de algoritmos com comandos pré-programados expressou um conjunto de aspectos técnicos e estéticos de acordo com os parâmetros previamente configurados. De fato, o advento das novas tecnologias digitais permitiu aos arquitetos projetar por meio de códigos e algoritmos (CECCATO, 2012). Com isso, a singularidade das formas de edifícios tem se tornado cada vez mais uma constante na atualidade. 
Simular caracteriza-se em um processo dinâmico, e tem como objetivo testar, validar e aferir situações cujos resultados poderão viabilizar melhores soluções projetuais. Com base nisso, Sanches e Amorim (2001) apontam que as simulações adquirem um papel fundamental nas escolhas de projeto. Programas computacionais viabilizam aferições simultâneas em diversos aspectos do projeto, cálculos complexos com agilidade, além de avaliações dos modelos com precisão de processamento (FONSECA; PEREIRA; CLARO, 2010).

As estratégias de projeto se restringem a correções e ações de reparo nas ocasiões em que a simulação é empregada apenas nas fases finais do processo de concepção (GONÇALVES; MOURA; KUNIOCHI, 2015). Dessa maneira, a probabilidade de adquirir melhores resultados quanto ao desempenho é maior quando utilizados softwares que avaliam as diversas funções no edifício desde estágios iniciais de projeto. Assim, as estratégias de intervenção não se restringirão à adaptação da forma e sim a soluções visando desempenho, função e forma da edificação (LYNCH, 2015).

O uso de simulação computacional possibilita estabelecer situações comparativas entre diversos resultados e variáveis distintas. No entanto, a fim de obter uma avaliação balizada por fatos testados pelas simulações, a interpretação dos resultados requer conhecimento técnico e crítico.

Logo se percebe que com a utilização da MP, diversos aspectos - técnicos, funcionais ou estéticos - do projeto podem ser pensados concomitantemente, como, por exemplo, a busca pela melhor solução quanto à insolação, iluminação natural, otimização da geometria, entre outros aspectos.

\section{Pesquisas anteriores acerca da iluminação natural e insolação na concepção arquitetônica}

É importante situar que a preocupação com proteção solar na concepção arquitetônica já ocorreu no decorrer do tempo, como, por exemplo, com os brise-soleil nas obras de Le Corbusier. Além disso, estudos quanto ao comportamento da luz natural em edifícios são apontados por Hopkinson (1963) através do uso de modelos físicos para avaliação ao ar livre ou mesmo através de lâmpadas simulando a luz solar. Todavia, é importante ressaltar as novas perspectivas que são abertas com o uso dos recursos computacionais.

Tem-se conhecimento de pesquisas relevantes em práticas projetuais de arquitetos (HUDSON; SHEPHERD; HINES, 2011; MILLER, 2011) que utilizaram MP; no entanto, trata-se de uma ferramenta pouco empregada no Brasil.

No projeto do Estádio Aviva, em Dublin, Hudson, Shepherd e Hines (2011) ilustram como foi projetar um edifício por meio de algoritmos. A forma da edificação, materiais da fachada, ventilação, entre outros aspectos foram tratados simultaneamente por meio de MP. Outro bom exemplo é a concepção do Hangzhou Tennis Center, na China, em que Miller (2011) demonstra como foram avaliados fatores como sombra, drenagem, desempenho estrutural e sistemas técnicos desportivos para definição final da forma.

Há também pesquisas teórico-experimentais que vislumbram novas possibilidades da utilização da MP para análise do comportamento da luz natural e insolação em projetos de arquitetura. Ercan e Elias-Ozkan (2015) exploraram alternativas para proteção solar, por meio de algoritmos, objetivando otimizar a iluminação natural e o bloqueio da radiação solar excessiva em edifícios de escritórios.

Eltaweel e Su (2017) avaliaram diferentes cenários de proteção solar em ambiente corporativo em Novo Cairo, Egito, visando distribuição da iluminação natural na área de trabalho. Tablada et al. (2018) realizaram estudo em edifício residencial em Singapura para instalação de placas fotovoltaicas e plantação agrícola como meio de sombreamento da fachada, identificando o melhor ângulo de inclinação dos painéis para receber maior radiação solar e ao mesmo tempo para proteção solar. A pesquisa de Jalali, Noorzai e Heidari (2019) avalia a otimização da radiação solar incidente e a forma do edifício de escritórios no Terã, por meio de algoritmos. Abdullah e Alibaba (2017) avaliaram sistemas fotovoltaicos como elementos de sombreamento responsivo da fachada de edifício comercial em Erbil, Iraque.

Como denotam as pesquisas supracitadas, há diversas aplicações da MP. Contudo há uma lacuna em estudos sobre investigação de edificações com geometrias torcidas, que atualmente são cada vez mais recorrentes. Na presente pesquisa esse tipo de edifício é investigado. 


\section{Método}

Os procedimentos metodológicos (Figura 1) tiveram início com a revisão da literatura acerca da bibliografia que envolve a relação entre a modelagem paramétrica de edificios torcidos, a iluminação natural e a radiação solar, respaldado por normas técnicas ${ }^{1}$, além disso, contato com escritórios autores de projetos de edifícios torcidos a fim de obter informações complementares. Posteriormente, foi realizada análise dos desenhos e das informações técnicas, configurando um banco de dados a respeito dos itens estudados (edifícios torcidos, aberturas da fachada, proteções solares). Foi analisada a carta solar com informações de temperaturas anuais, a fim de identificar o período crítico, caracterizado pelos dias e horários que apresentam maior insolação, para definição das simulações.

Na sequência foram definidos os parâmetros a serem utilizados nos experimentos, levando em consideração a extensa pesquisa realizada, e foram concebidos os algoritmos do edifício modelo, proteções solares e trajetória solar, assim como os algoritmos para simulações considerando os dados cartográficos da cidade de São Paulo. Ademais, foram realizadas as simulações, aferidos os resultados e realizadas discussões. O processo de projeto configurou-se pela modelagem paramétrica seguida da simulação e posterior verificação e modificação.

Figura 1 - Fluxo de trabalho
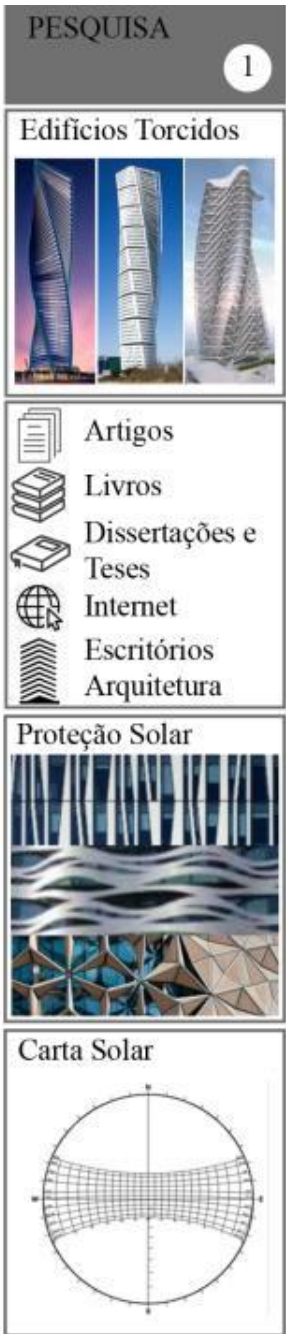

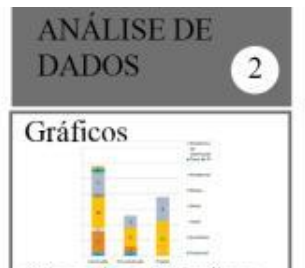

Desenhos Técnicos

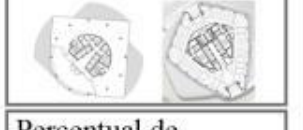

Percentual de Abertura da Fachada (PAF)
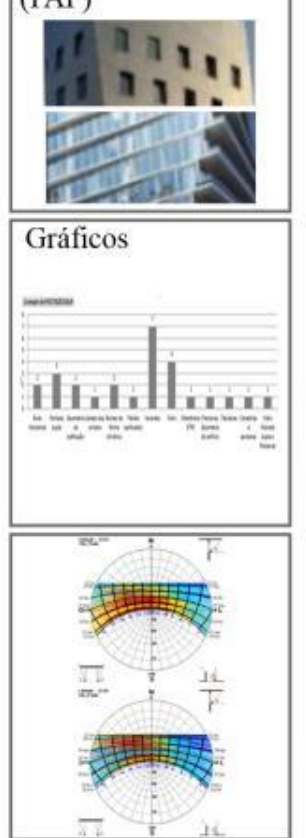

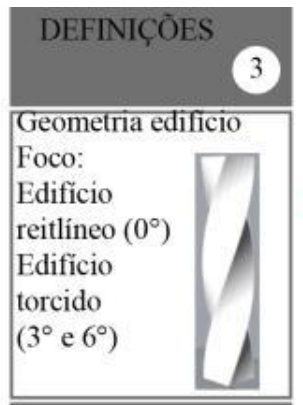

Percentual de Abertura da Fachada (PAF) $29 \%, 37 \%$, $40 \%, 50 \%$, $81 \%$

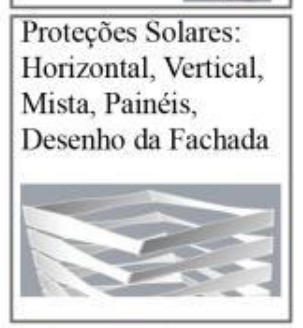

Dias e horários para simulações com base na análise do perídoco crítico

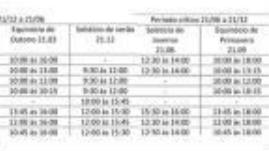

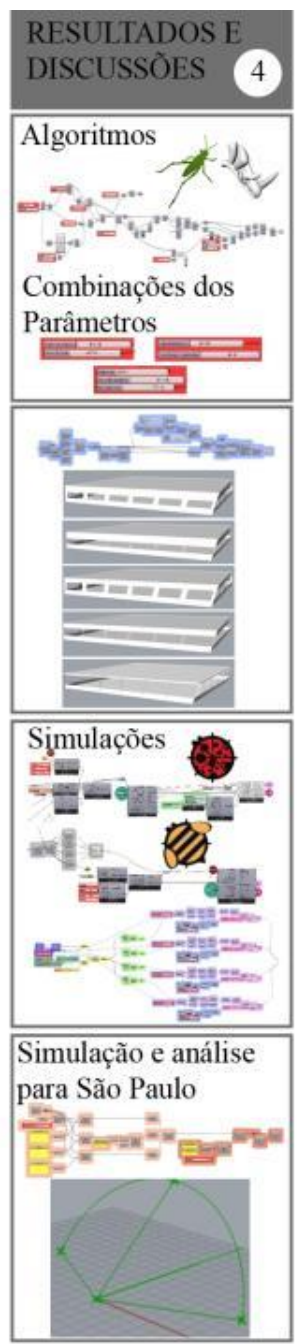

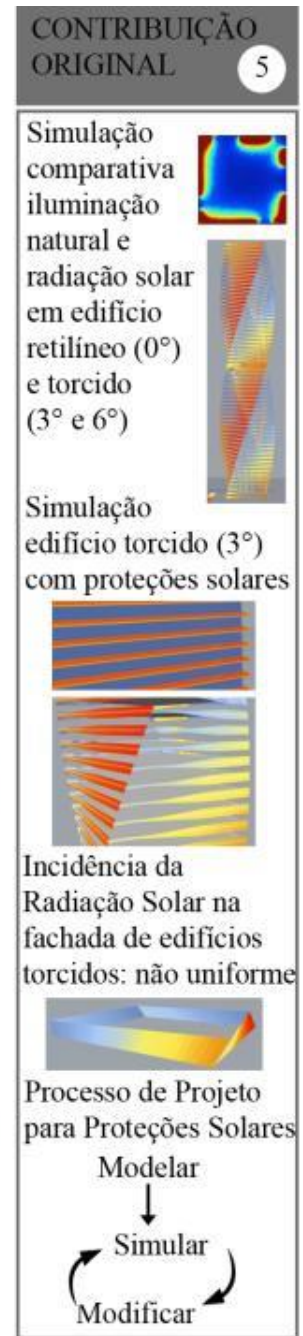

Fonte: desenvolvido pela autora Camila Leone para este artigo.

${ }^{1}$ NBR 15220-1 (ABNT, 2005a), NBR ISO/CIE 8995-1 (ABNT, 2013a), NBR 15215-1 (ABNT, 2005b) e NBR 15575-1 (ABNT, 2013b). 


\section{Critérios para parâmetros do edifício modelo}

A presente pesquisa realizou o levantamento de 61 edifícios com geometria torcida (Figuras 2 e 3 ), tanto construídos como em fase de construção ou projetos, que basearam a configuração do edifício modelo (LEONE, 2017). Nesse levantamento constatou-se que os edifícios torcidos, ou de dupla curvatura, apresentavam rotações por andar entre 0,48 e 8 graus. Assim, o primeiro parâmetro foi realizar experimentos com rotações de 3 e 6 graus.

Para definição das características do edifício modelo, foi levado em consideração o estudo desenvolvido por Marcondes (2010), que apresenta a configuração de edifícios de escritórios situados na cidade de São Paulo. Segundo a pesquisa de Marcondes (2010), os edifícios de escritórios apresentam predominância das lajes dos pisos em formatos quadrados e retangulares, com leiaute livre e core central. Nas fachadas observou-se a redução da área de transparência das edificações (window too wall ratio - wwr) de até 100\% para cerca de $50 \%$, variando de $40 \%$ a $60 \%$ da área transparente da fachada (MARCONDES, 2010).

Com base nessas informações, o edifício modelo para os experimentos desenvolvidos possui planta quadrada, com dimensões de 30x30 metros, e core central. A altura adotada de piso a piso foi de 3,24 metros, e pé-direito de 2,64 metros, considerando a circulação vertical de 18 degraus com espelhos de $18 \mathrm{~cm}$ cada um.

Figura 2 - Levantamento de 61 edifícios com geometria torcida
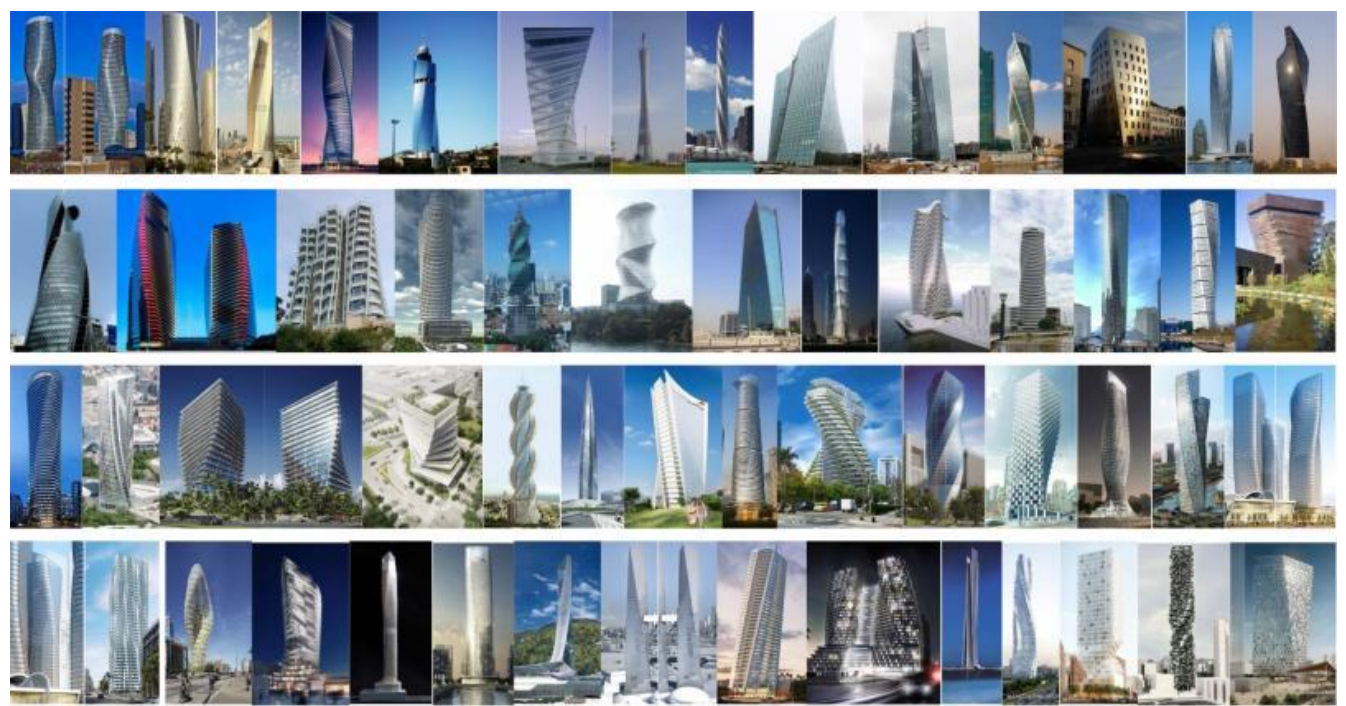

Fonte: adaptado de Leone (2017).

Figura 3 - Edifícios torcidos e respectivos usos

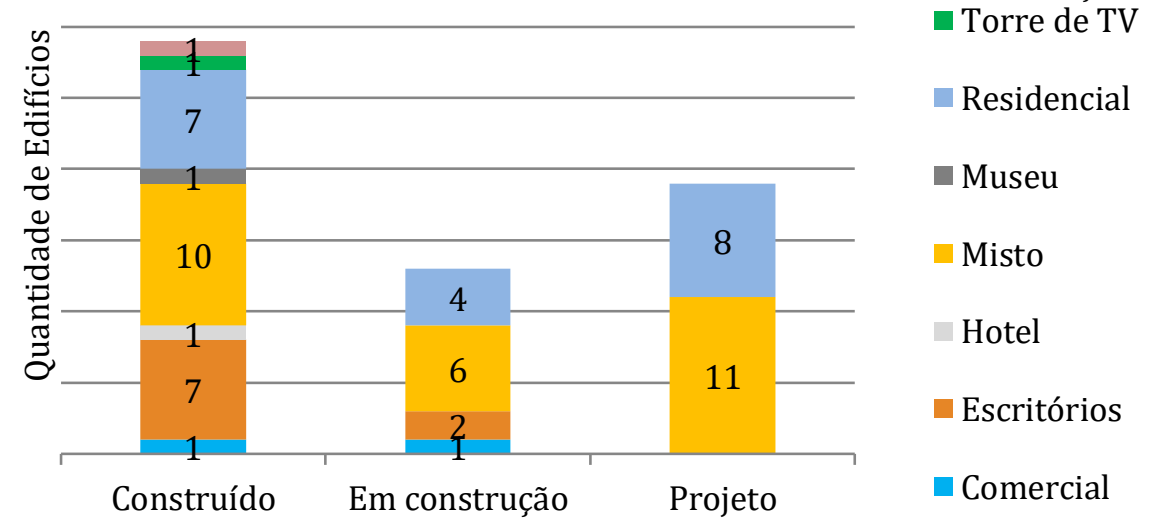

Fonte: Leone (2017).

252 Leone, C.; Florio, W. 
Como será visto no próximo item, um conjunto de parâmetros foi inserido nos algoritmos criados para a definição da geometria do edifício modelo, permitindo:
(a) variações quanto à geometria (forma) dos edifícios;
(b) dimensões da base da edificação;
(c) rotação;
(d) altura;
(e) quantidade de pavimentos; e
(f) dimensões das janelas.

A partir da combinação entre esses parâmetros foi concebido um conjunto de edifícios retilíneos e torcidos.

\section{Parâmetros para MP dos elementos do edifício modelo}

A pesquisa foi desenvolvida por meio da modelagem e simulação paramétrica, com o plug-in Grasshopper, Ladybug e Honeybee (Figura 4). A partir dos parâmetros mencionados no item anterior, no ambiente computacional, foram desenvolvidos os seguintes elementos arquitetônicos:

(a) torre do edifício em formato retilíneo e torcido (este com $3^{\circ}$ e $6^{\circ}$ de torção) - experimento 1 (Figura 7);

(b) janelas da fachada com cinco diferentes percentuais de abertura da fachada (PAF), a saber, com $29 \%$, $37 \%, 40 \%, 50 \%$ e $81 \%$ (Figura 5); e

(c) proteções solares em configuração horizontal, vertical, mista (horizontal/vertical), painéis e desenho da fachada - experimentos 2 a 6 respectivamente (Figura 7).

\section{Figura 4 - Algoritmos com as etapas da MP e das simulações}

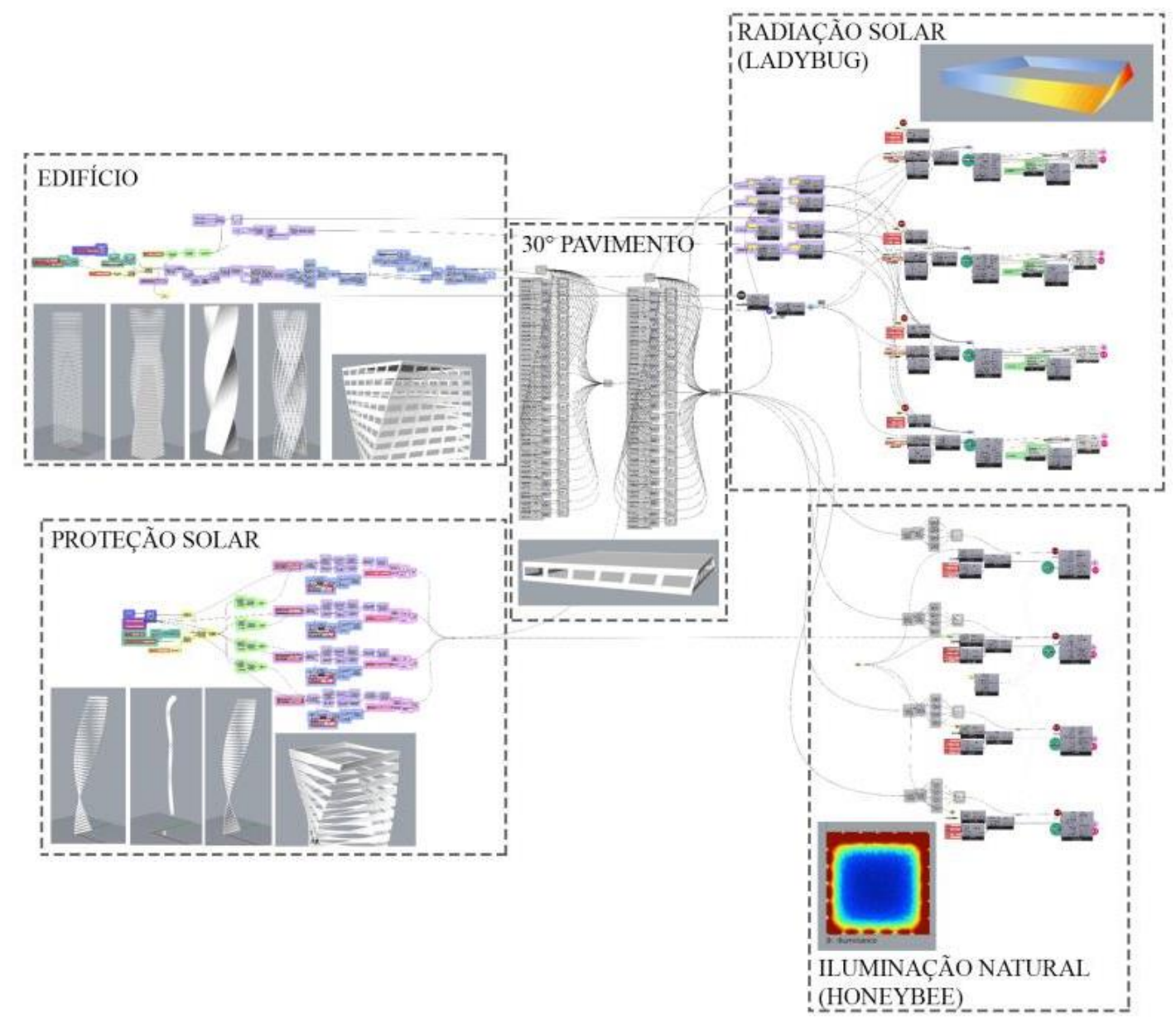

Fonte: desenvolvido pela autora Camila Leone para este artigo. 
Figura 5 - Configuração das aberturas estudadas com percentual de transparência das fachadas

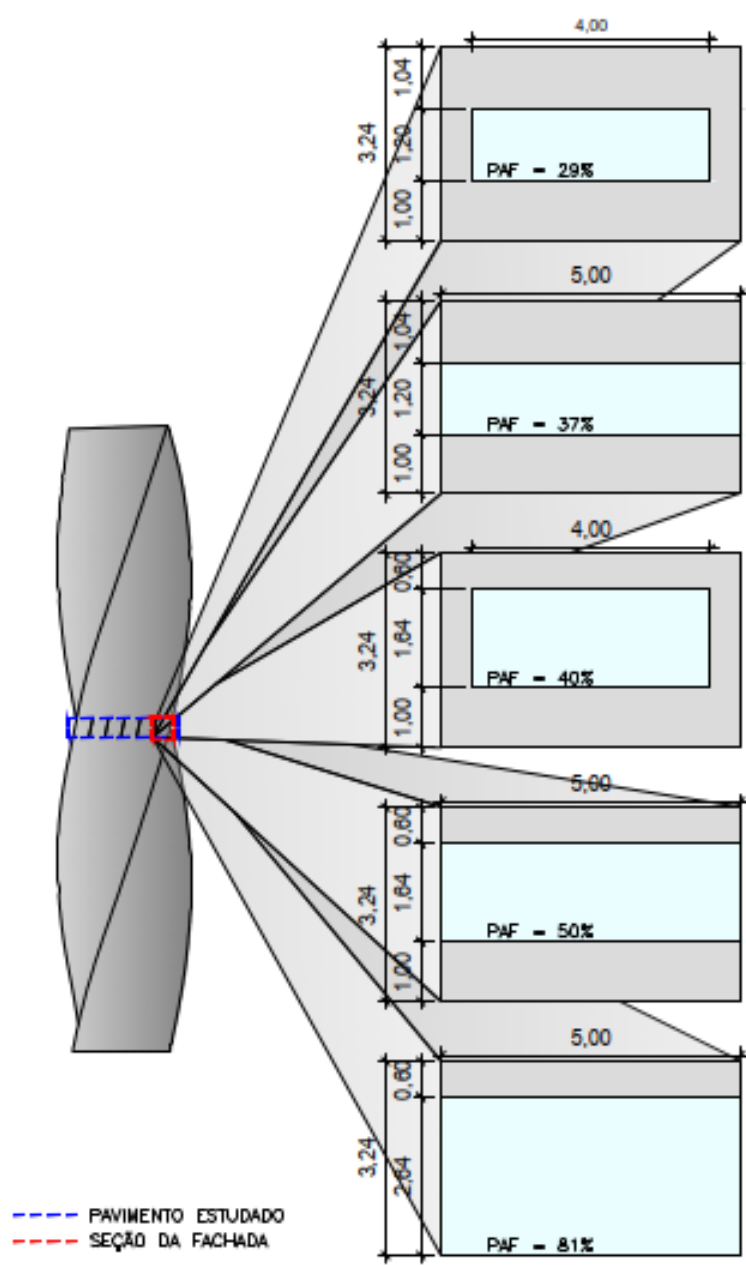

Fonte: desenvolvido pela autora Camila Leone para este artigo.

As configurações das aberturas estão ilustradas na Figura 6, enquanto o percentual de transparência das fachadas está ilustrado na Figura 5.

\section{Definição dos experimentos}

Com o propósito de comparar diferentes percentuais de transparência das janelas da fachada, assim como de diferentes tipos de proteção solar - horizontal, vertical, mista, painel e desenho da fachada - foram realizados 6 experimentos no programa Rhinoceros com os plug-ins Grasshopper, Ladybug e Honeybee para avaliação da iluminação natural no interior de um edifício modelo e a incidência de radiação solar na fachada.

Os seis experimentos realizados tiveram quatro objetivos:

(a) investigação do comportamento da iluminação natural no interior do edifício a partir da variação das dimensões das áreas de janelas;

(b) investigação da incidência da radiação solar sobre a fachada (envoltória do edifício);

(c) avaliação de proteções solares sobre a envoltória, considerando as necessidades especificas da geometria torcida e de cada orientação;

(d) inter-relação entre a radiação solar e iluminação natural, comparando a geometria retilínea à forma torcida do edifício modelo. 
Figura 6 - Configuração das aberturas

Dimensões Janelas (Comprimento x Altura)

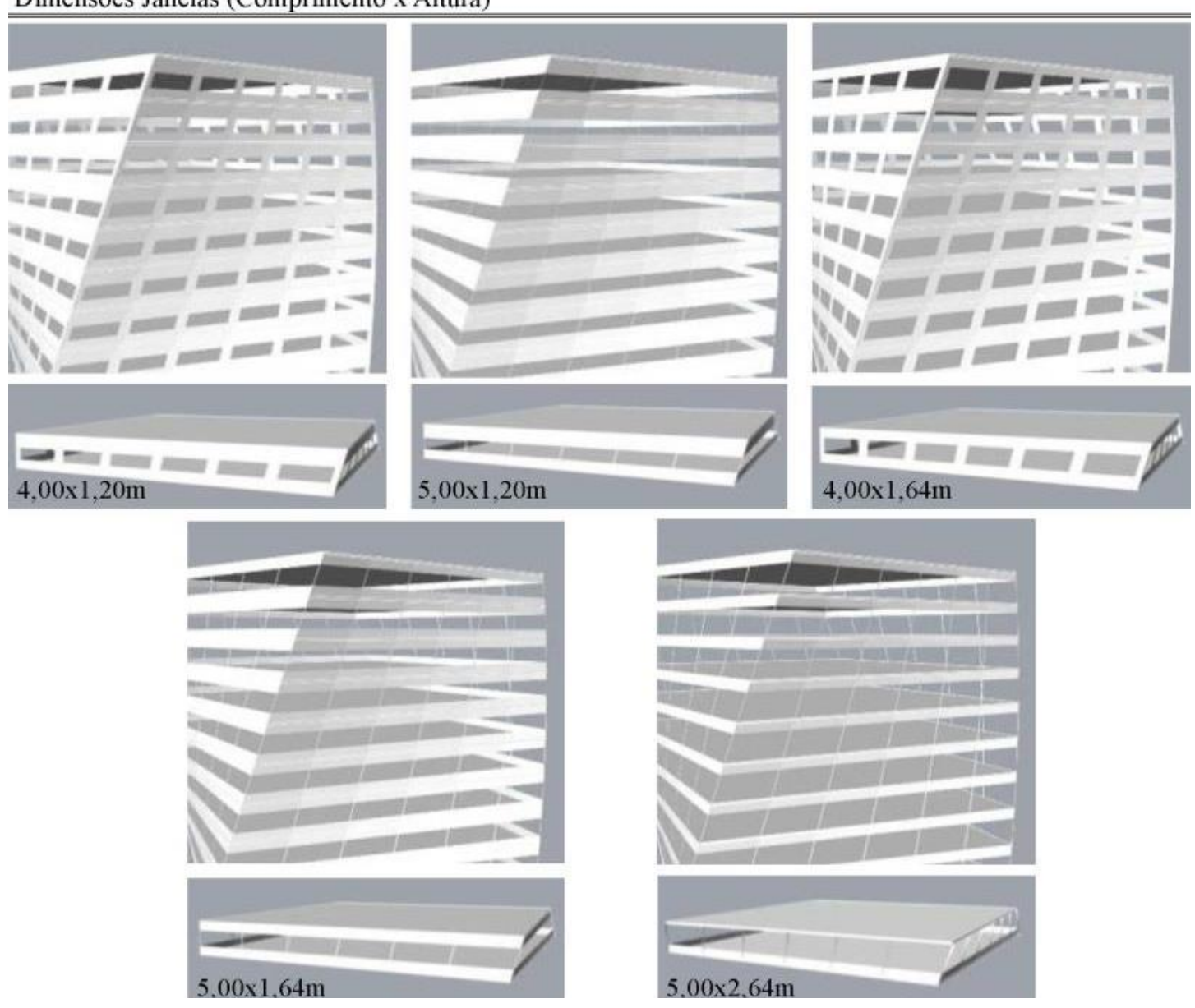

Fonte: adaptado de Leone (2017).

Para análise do comportamento da iluminação natural, foram estabelecidos cinco diferentes percentuais de abertura das janelas da fachada (PAF) - 29\% de área translucida luminosa; 37\%, 40\%, 50\% e 81\%, com diferentes dimensões de largura e altura da área envidraçada. É importante destacar que para o cálculo da porcentagem de transparência da fachada foi considerado o perímetro total do pavimento (Figura 5).

\section{Critérios para as simulações}

Para as simulações foram adotados os dias referentes ao equinócio de outono (21/03), solstício de inverno (21/06), equinócio de primavera (23/09) e o solstício de verão (21/12), sobretudo por apresentarem altura e posicionamento solares distintos e características particulares quanto às condições climáticas.

Os horários para as simulações de radiação solar e de iluminação natural foram definidos a partir da análise das temperaturas da Carta Solar, disponíveis no software SOL-AR, desenvolvido pela Universidade de Santa Catarina (Laboratório de Eficiência Energética em Edificações). A fim de identificar os horários correspondentes ao período crítico (maiores temperaturas) na cidade de São Paulo, foram avaliadas oito orientações do edifício: norte, nordeste, leste, sudeste, sul, sudoeste, oeste, noroeste. Os horários, predominantemente nos períodos críticos, foram $10 \mathrm{~h} 00$ e $15 \mathrm{~h} 30$.

\section{Investigação da iluminação natural e radiação solar pelo plug-in Honeybee e Ladybug}

A investigação da iluminação natural no ambiente interno, assim como a análise da incidência da radiação solar na fachada do edifício modelo, foi realizada por meio do plug-in Honeybee e Ladybug. Assim, enquanto o Ladybug avalia a radiação solar na fachada do edifício, o Honeybee permite avaliar a distribuição 
da iluminação natural no interior do ambiente. Como será visto adiante, os resultados são apresentados através de gradações de cores, que indicam o fator de iluminância e de radiação solar.

Esses recursos paramétricos de modelagem e de simulação foram adotados para gerar e comparar as diferentes dimensões das janelas e identificar soluções para proteções solares. A trajetória solar foi simulada parametricamente com base nos dados cartográficos da cidade de São Paulo.

As simulações computacionais no plug-in Honeybee e Ladybug foram realizadas para o $30^{\circ}$ andar do edifício modelo, com 60 pavimentos, devido ao fato de representar o ponto médio de um hipotético edifício de grande altura.

A escolha dos plug-ins justifica-se devido à grande utilização em escritórios na atualidade, e estudos empíricos acadêmicos relevantes, que abordam MP como ferramenta para desenvolvimento de projetos. Em território nacional, o uso de algoritmos ainda é pouco utilizado, tendo maior destaque em alguns centros de pesquisa e universidades. Os plug-ins utilizam, como base de dados, as informações disponibilizadas pelo Instituto Nacional de Meteorologia (INMET) elaborado por Roriz (2012).

\section{Definição dos parâmetros para os experimentos: edifício e tipos de proteções solares}

As proteções solares foram geradas parametricamente por meio de algoritmos, visando proporcionar soluções independentes a cada orientação do edifício, e, também, de acordo com as necessidades específicas de cada fachada. Em alguns casos, a alternativa adotada reflete inclusive uma solução estético-funcional ao edifício. A customização dos parâmetros para cada tipo de proteção e do edifício modelo podem ser verificadas na Figura 7. Embora tenha sido prevista parametrização de diversos componentes sendo possíveis inúmeras combinações entre os parâmetros, foram utilizadas, no entanto, algumas das combinações.

\section{Resultados obtidos}

Como vimos em Critérios para parâmetros do edifício modelo, no levantamento sobre edifícios altos com geometrias torcidas, isto é, dotados de superfícies externas de dupla curvatura, observou-se a predominância de edifícios com rotação (a partir de um eixo central) entre $0,48^{\circ}$ a $8^{\circ}$ por andar. Assim, decidiu-se realizar um experimento (la e $1 \mathrm{~b}$ ) inicial, com rotações de $0^{\circ}, 3^{\circ}$ e $6^{\circ}$ por andar, a partir de um eixo central, e, depois, 5 experimentos, de 2 a 6 , com rotação apenas de $3^{\circ}$.

$\mathrm{Na}$ fase inicial, o experimento la consistiu no estudo do comportamento da luz natural, realizando simulações com o edifício retilíneo e os torcidos (3 e 6 graus), com diferentes percentuais de transparência da fachada. No experimento $1 b$ analisou-se a incidência de radiação solar na envoltória em ambos os edifícios analisados, ortogonal e com torções ( 3 e 6 graus). Após os experimentos iniciais, os experimentos 2 a 6 foram efetuados para avaliar a iluminação natural e a radiação solar na fachada da edificação, com o edifício torcido somente com $3^{\circ}$ por andar, e abertura da fachada em $81 \%$ com cada tipo de proteção solar desenvolvida (Figura 8).

Os resultados das simulações iniciais, sobretudo das proteções solares, geraram a necessidade de alterações no projeto modelo inicial. Consequentemente, foram propostas alterações do projeto de modo a atender ao melhor desempenho.

Para tanto, com o propósito de investigar as necessidades específicas do edifício, adotou-se o conceito de performance-based design como estratégia para alcançar melhores soluções de projeto, no qual o desempenho é avaliado na fase de criação do projeto.

Reconhece-se que a busca por resultados mais satisfatórios para o conforto no interior do edifício, assim como para sua maior eficiência, está atrelada a diversos fatores, tais como, materiais eficientes (vidros especiais de controle solar); impacto das edificações do entorno; etc. Todavia, nesta pesquisa a delimitação do estudo se restringe em analisar apenas a relação entre o formato das aberturas e das proteções solares sobre o desempenho da iluminação natural e incidência dos raios solares no interior do edifício.

Os 6 experimentos a seguir consistiram em avaliar a iluminação natural, com diferentes configurações de janelas, e a radiação solar incidente, identificando a relação entre torção, autossombreamento e incidência de luz natural. A avaliação identificou particularidades referentes às diferentes orientações do edifício, a fim de empregar um processo de projeto com propostas quanto à disposição de elementos de proteção solar e estratégias, e, também, visando maximizar a iluminação e minimizar a incidência da radiação solar. 
Figura 7 - Edifício e tipos de proteção solar dos experimentos
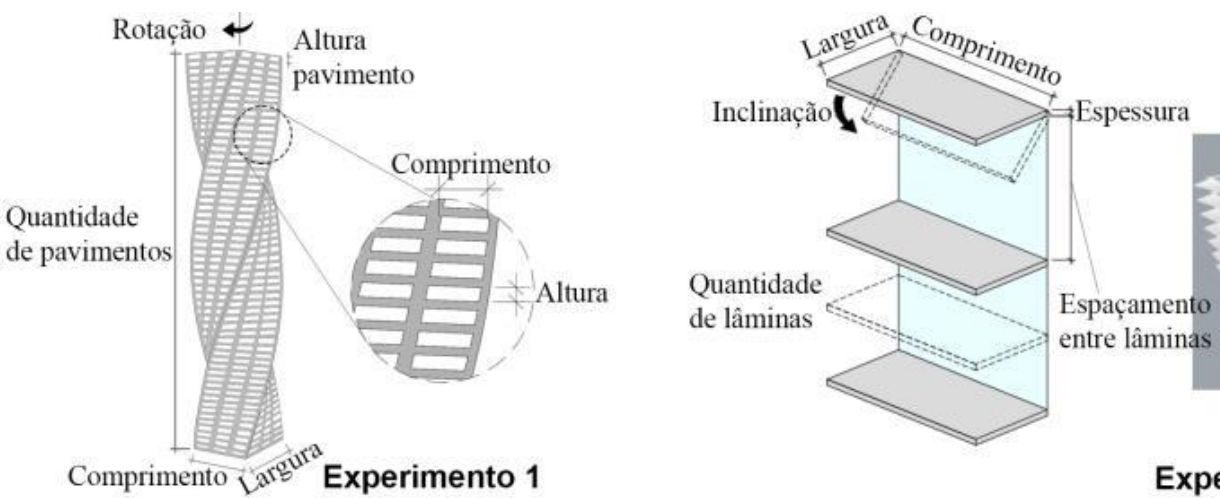

Experimento 2

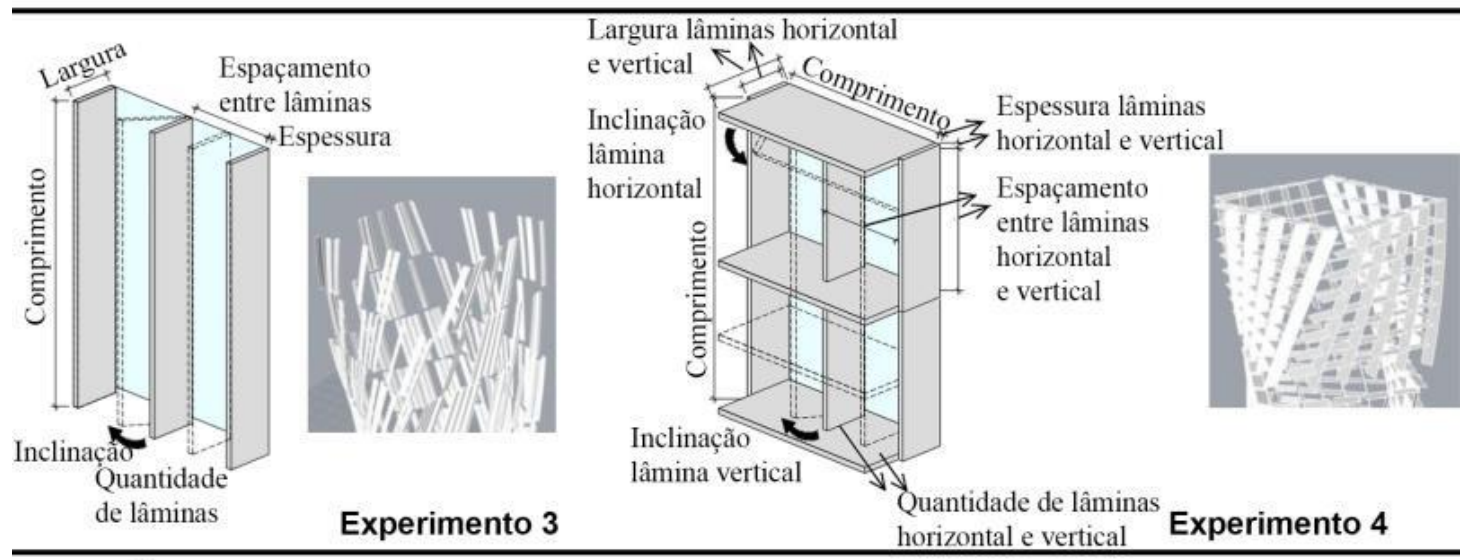

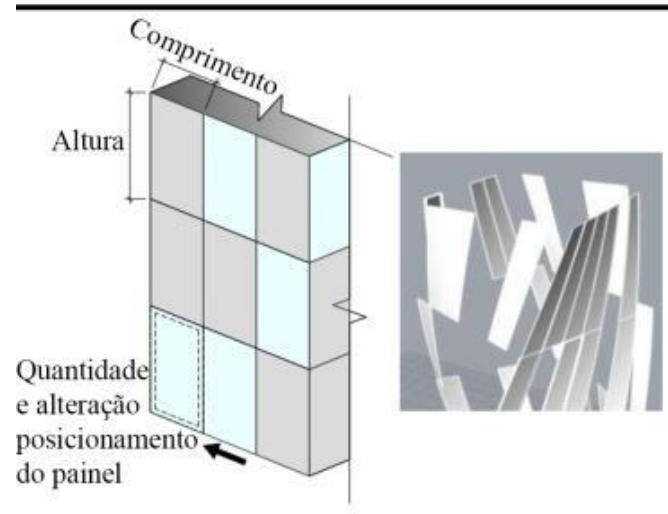

Experimento 5

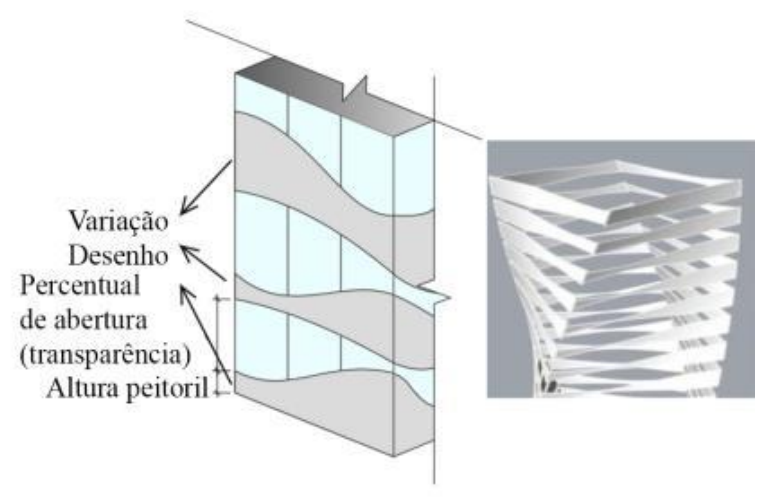

Experimento 6

Fonte: desenvolvido pela autora Camila Leone para este artigo. 
Figura 8 - Parâmetros das simulações realizadas nos 6 experimentos

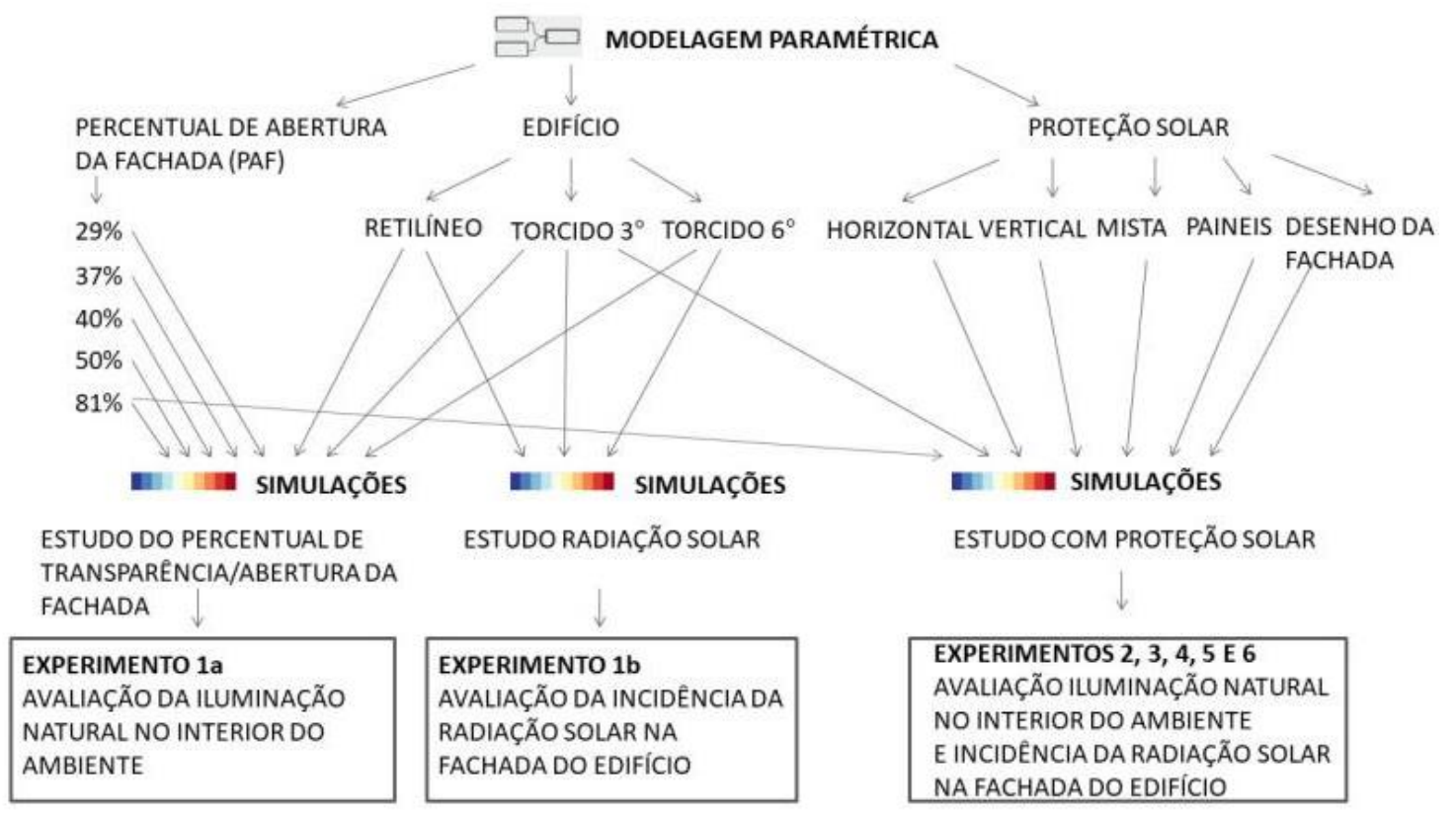

Fonte: desenvolvido pela autora Camila Leone para este artigo.

\section{Experimento 1a: análise da iluminação natural no interior do edifício}

Como era esperado, os resultados das análises das simulações para avaliação do comportamento da iluminação natural do primeiro experimento demonstraram que nas áreas próximas às janelas há maior iluminância, que tende a decrescer à medida que se afasta delas. Em ambientes cuja envoltória apresenta torção, é possível observar assimetria do comportamento da iluminação decorrente da angulação da fachada em relação ao piso. Além disso, nos ambientes com maior torção, observou-se decréscimo de incidência da iluminação natural, enquanto no edifício com geometria com menor torção, obteve-se melhores resultados para iluminância no interior do ambiente.

A Figura 9 apresenta a simulação às $10 \mathrm{~h}$ da configuração de maior percentual de transparência da fachada, ou seja, com $81 \%$ de abertura. Entretanto os resultados mantiveram-se também nas outras simulações (15h30min e demais configurações de janelas).

\section{Experimento 1b: incidência da radiação solar na envoltória do edifício}

Em comparação com o edifício retilíneo, as simulações de radiação solar no edifício com geometria torcida, com rotação de eixo central de $3^{\circ}$ e $6^{\circ}$, demonstraram que a torção do edifício contribui para que a fachada possua menor área de incidência da radiação. Portanto, para radiação solar, a torção favorece o autossombreamento da envoltória, e quanto maior a torção, mais a superfície fica protegida. Por outro lado, os locais de maior incidência da radiação possuem maior ordem de grandeza da incidência $\mathrm{kWh} / \mathrm{m}$, devido ao ângulo da fachada em relação ao posicionamento do sol nas datas e horários da simulação (Figura 10).

Na Figura 10, as imagens demonstram a incidência da radiação solar em um pavimento do edifício. Ainda que seja visualizada a face interna de uma das orientações da edificação, ela reflete a mesma gradação de cores que ocorre do lado externo do edifício e, nessa forma de apresentação, permite a visualização de todo o perímetro do pavimento.

Comparando o período das $10 \mathrm{~h} 00$ com o das $15 \mathrm{~h} 30$, nas datas estudadas, as simulações demonstraram maior concentração da radiação solar incidente na fachada no mês de junho. Esse resultado pode ser explicado pela Lei do Cosseno ou Lei de Lambert, desenvolvida por Johann Heinrich Lambert no século XVIII. Segundo esse postulado, a maior concentração de radiação ocorre através do menor ângulo entre o zênite e o raio solar, pois à medida que os raios solares ficam perpendiculares à linha do horizonte, a mesma quantidade de energia se distribui em uma área menor, resultando em maior incidência de radiação. 
Figura 9 - Experimento 1a - Análise da iluminação natural (comparação edifício ortogonal e torcidos)
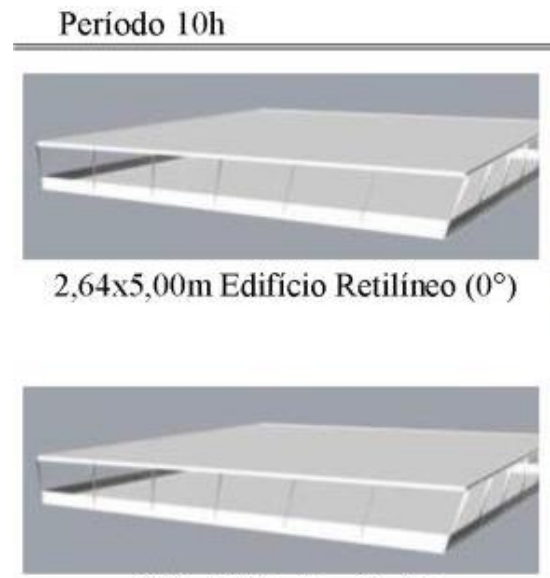

$2,64 \times 5,00 \mathrm{~m}$ Torção $3^{\circ}$

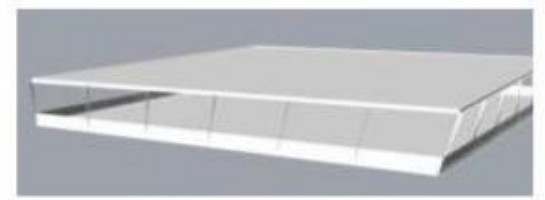

$2,64 \times 5,00 \mathrm{~m}$ Torção $6^{\circ}$
$21 / 03$
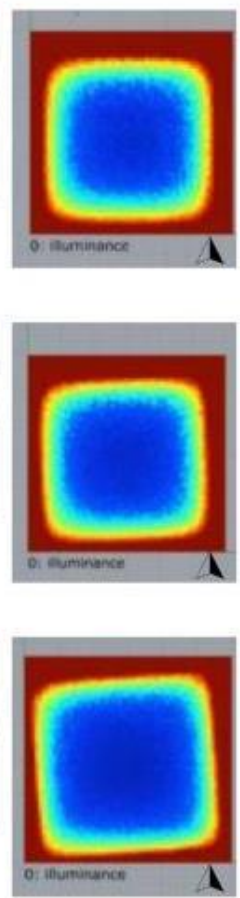

21/06
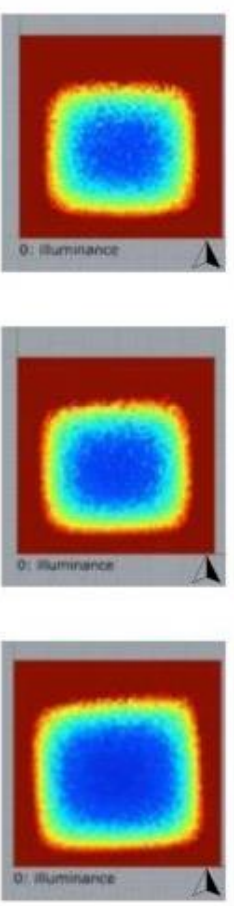

$23 / 9$
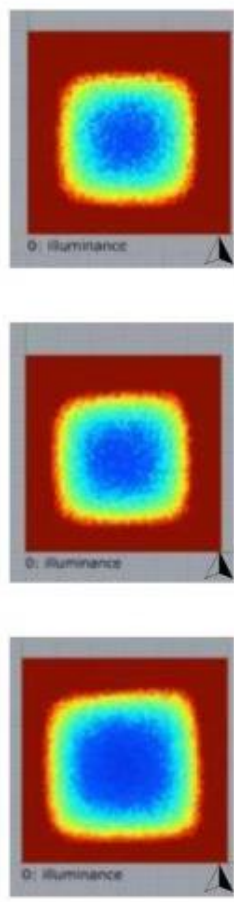

$21 / 12$
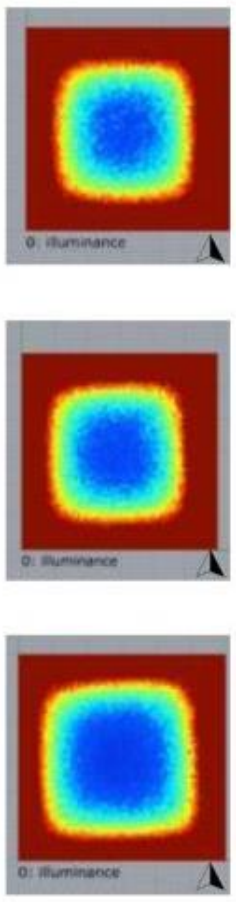

Legenda (em Lux)

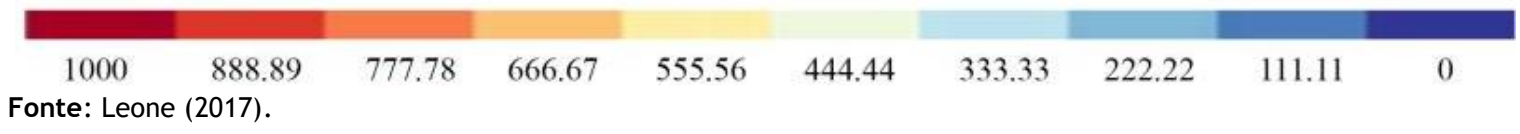

Figura 10 - Experimento 1b - Incidência da radiação solar na envoltória do edifício (comparação edifício ortogonal e torcidos)

Período $10 \mathrm{~h}$ às $15 \mathrm{~h} 30 \mathrm{~min}$.

$$
21 / 03
$$

21/06

$23 / 9$

$21 / 12$

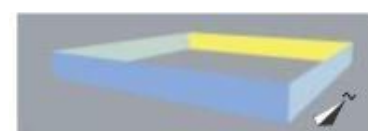

Edifício Retilíneo $(0$
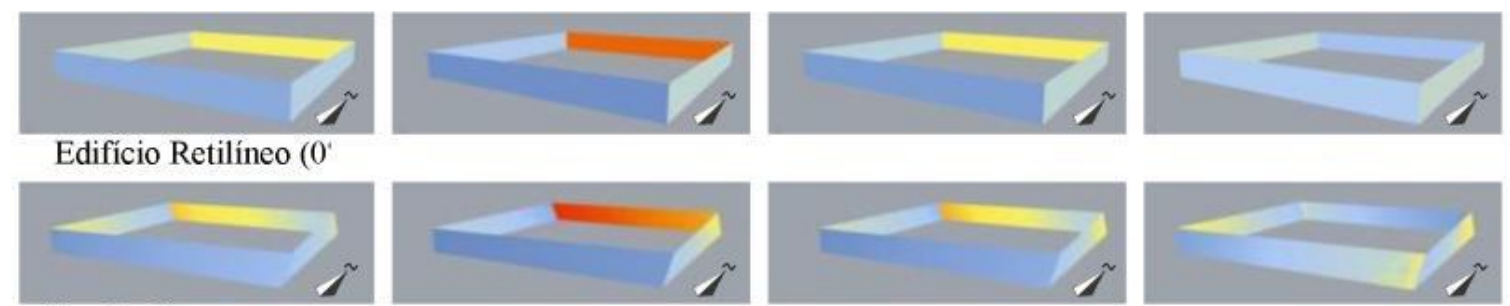

Torção $3^{\circ}$
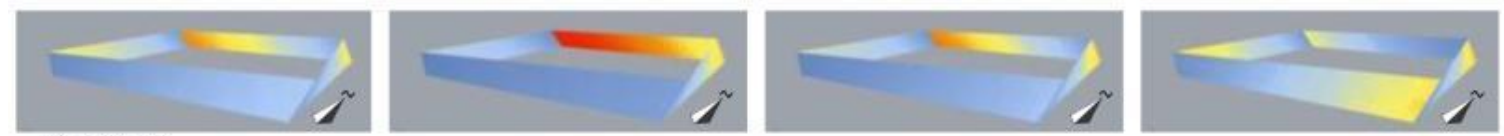

$$
\text { Torção } 6^{\circ}
$$

Legenda $\left(\mathrm{em} \mathrm{kWh} / \mathrm{m}^{2}\right)$

\begin{tabular}{ccccccccccc}
\hline 0 & 0.35 & 0.7 & 1.05 & 1.40 & 1.75 & 2.10 & 2.45 & 2.80 & 3.15 & 3.50 \\
Fonte: Leone & $(2017)$.
\end{tabular}


Nos experimentos, a radiação solar foi estudada em relação à fachada do edifício; dessa maneira, a posição do sol no inverno resultou em uma área de incidência menor na envoltória e, portanto, com maior incidência da radiação, se comparado às outras datas estudadas.

Além disso, é possível observar a uniformidade quanto à incidência da radiação solar nas fachadas do edifício retilíneo, e, dessa maneira, apenas uma análise da carta solar torna-se suficiente para propor soluções de projeto. No entanto, à medida que o edifício é torcido, observamos a não uniformidade da radiação solar, tornando-se únicas as necessidades quanto à proteção adequada.

A grande contribuição em utilizar simulações está justamente em identificar quais os locais exatos que o pavimento requer proteção. Ademais, cada pavimento apresentará necessidades específicas e, portanto, soluções únicas.

\section{Proteção solar}

Para esta etapa da pesquisa, experimentos de 2 a 6 , foi utilizada a geometria torcida de $3^{\circ}$ por representar a configuração, dentre as estudadas (3 e 6 graus), com melhor desempenho quanto à iluminação. Foi adotado o índice de transparência de $81 \%$, devido à maior exposição solar se comparado às demais configurações.

Quanto à iluminação natural, as simulações foram realizadas às 10h e $15 \mathrm{~h} 30$ para solstícios e equinócios. Porém, a radiação solar na fachada foi analisada no solstício de inverno por configurar-se no período em que apresenta maior radiação incidente na envoltória.

A seguir veremos como os resultados das simulações quanto à radiação solar incidente sobre a superfície da fachada contribuem para identificar o melhor ângulo de proteção solar capaz de nortear a instalação do quebra-sol.

\section{Experimento 2: proteção horizontal}

Em um primeiro momento, a proteção horizontal foi aplicada ao edifício modelo de modo que todas as fachadas tivessem a mesma configuração. A proteção fixa possui $34 \mathrm{~cm}$ de largura e espaçamento de $50 \mathrm{~cm}$.

A configuração com as mesmas dimensões de proteção para todas as fachadas resultou em soluções de proteção solar superdimensionadas para determinada face do edifício, ou aquém das necessidades em outra. Como resultado, pode-se perceber que a proteção apenas foi eficaz para as fachadas norte e leste no período das $10 \mathrm{hs}$. Às $15 \mathrm{~h} 30$, mesmo com o quebra-sol, a radiação continuava a incidir em toda a fachada norte e oeste. A fim a proteger a fachada da radiação excessiva, por meio da utilização de protetores solares, a simulação foi realizada para identificar o comportamento dos elementos estudados, e necessidades de alterações no projeto (Figuras 11 e 12). A proposta com lâminas fixas e dispostas igualmente em toda a envoltória do edifício demonstrou-se ineficiente para o período crítico estudado. Nesse sentido, é notória a relevância do processo de projeto com simulações e adequações conforme sugerido nos demais experimentos.

\section{Experimento 3: proteção vertical}

O posicionamento da proteção solar em formato vertical foi consequência da análise dos resultados da radiação solar incidente na fachada do edifício. Dessa maneira, foi priorizado o menor espaçamento entre as lâminas de proteção nos locais que as simulações de radiação solar indicaram maior índice de Kwh $/ \mathrm{m}$. Essa customização foi viável, uma vez que os elementos são configurados parametricamente, com variações prédefinidas quanto ao espaçamento entre os brises, assim como a quantidade de elementos nas diferentes orientações do edifício.

Com a inserção da proteção solar, as simulações demonstraram diminuição dos índices de iluminação natural no interior do ambiente. Em todo caso, essa situação seria uma consequência em qualquer edifício. Os resultados são apresentados em gradações de cores, sendo que a vermelha representa maior iluminância e a cor azul menor iluminância (Figura 13).

O diferencial em relação ao uso de simulações está justamente em identificar os locais que possuem maior incidência de radiação solar, e garantir maior quantidade de elementos de proteção solar, avaliando simultaneamente qual a relação ótima para alcançar a eficiência de sombreamento e permeabilidade da luz.

As áreas assinaladas em vermelho possuem maior radiação solar incidente, portanto são as áreas nas quais foram priorizados menores espaçamentos entre os elementos de proteção. A cor azul representa locais com 
menor incidência da radiação, e, por sua vez, com menor necessidade de proteção solar, priorizando maiores aberturas (Figura 14).

Observa-se que cada pavimento poderia apresentar uma solução individualizada por meio da exploração de parâmetros e variáveis, que podem ser configuradas nos algoritmos. Esse método explora diferentes alternativas, ao contrário da concepção em voga na maioria dos edifícios "tradicionais", que se configuram pela repetição da forma e utilização de pavimentos-tipo, gerando previsibilidade e simplificação que se dá pela repetição.

Figura 11 - Iluminação natural às $10 \mathrm{~h} 00$ e $15 \mathrm{~h} 30$, com $3^{\circ}$ de torção por pavimento

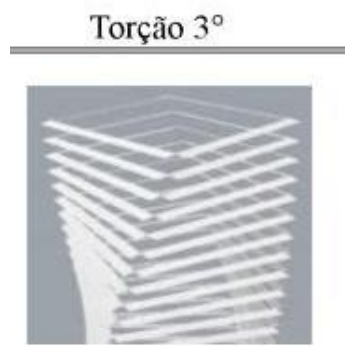

$10 \mathrm{~h}$
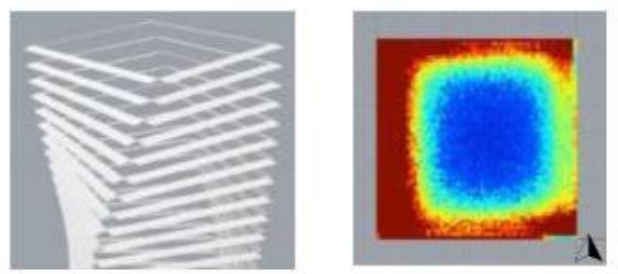

$15 \mathrm{~h} 30 \mathrm{~min}$

$21 / 03$

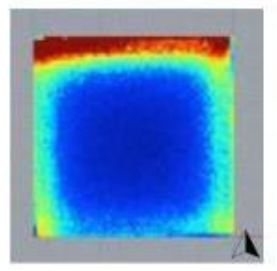

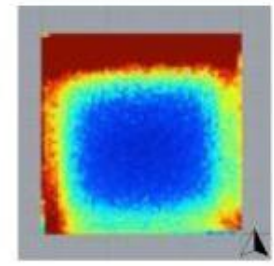
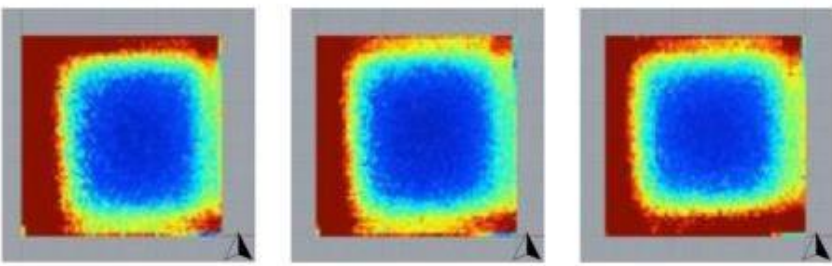

Legenda (em Lux)

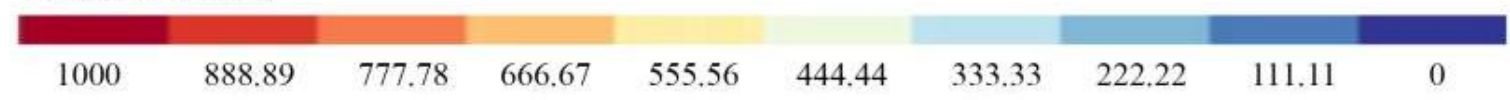

Fonte: Leone (2017).

Figura 12 - Radiação solar na fachada às $10 \mathrm{~h}$ e $15 \mathrm{~h} 30$, com $3^{\circ}$ de torção

Torção $3^{\circ} \quad 21 / 06$

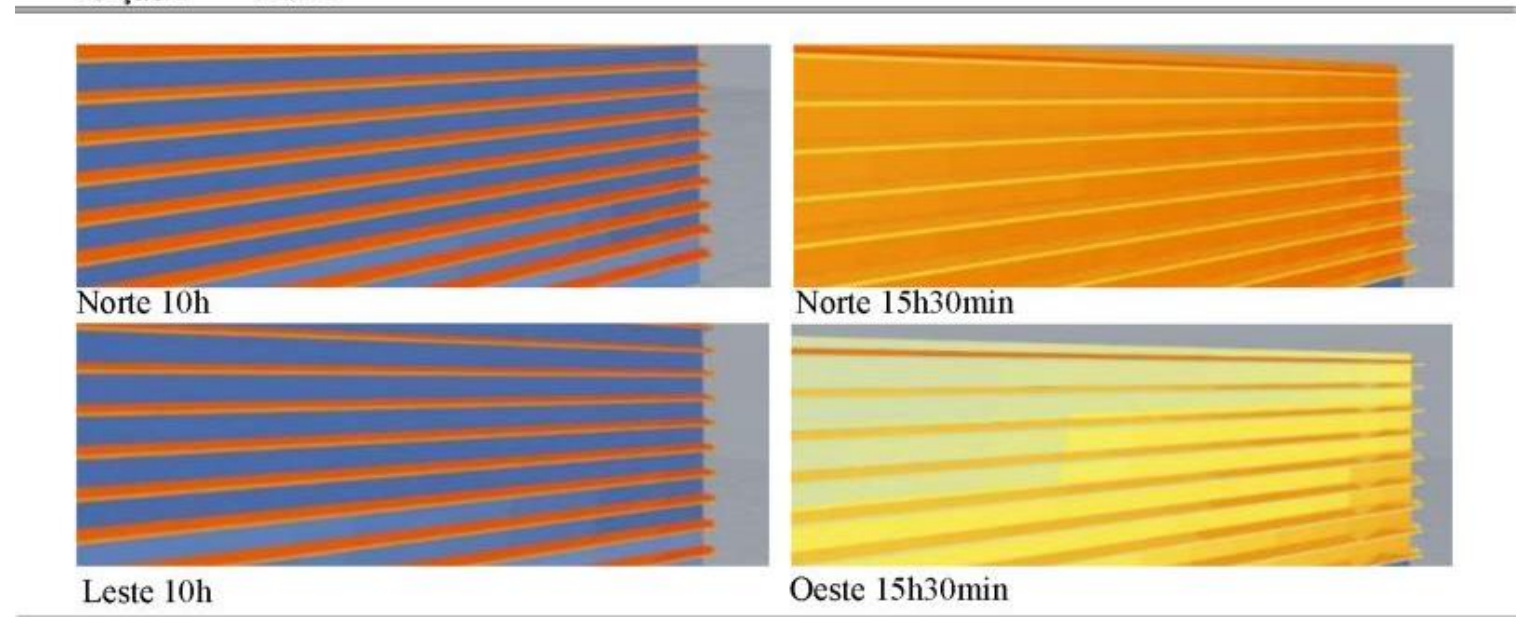

Legenda $\left(\mathrm{em} \mathrm{kWh} / \mathrm{m}^{2}\right)$

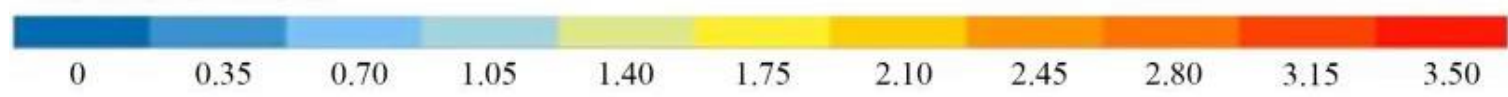

Fonte: Leone (2017). 
Figura 13 - Iluminação natural com proteção vertical às $10 \mathrm{~h}$ e $15 \mathrm{~h} 30$

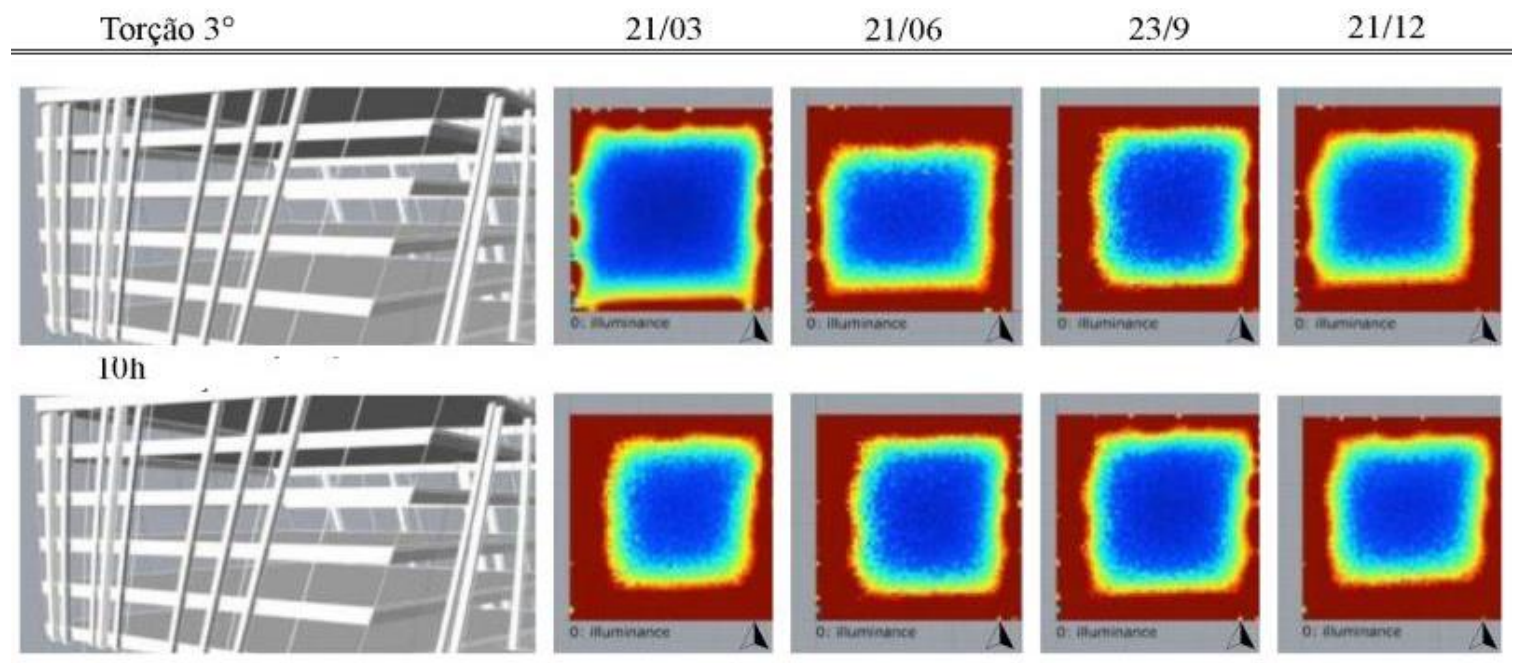

$15 \mathrm{~h} 30 \mathrm{~min}$

Legenda (em Lux)

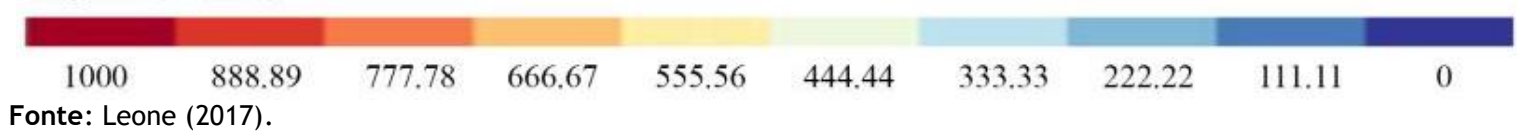

Figura 14 - Incidência da radiação solar em edifício com proteção vertical às $10 \mathrm{~h}$ e $15 \mathrm{~h} 30$

Fachada Norte Torção $3^{\circ}$ 21/06

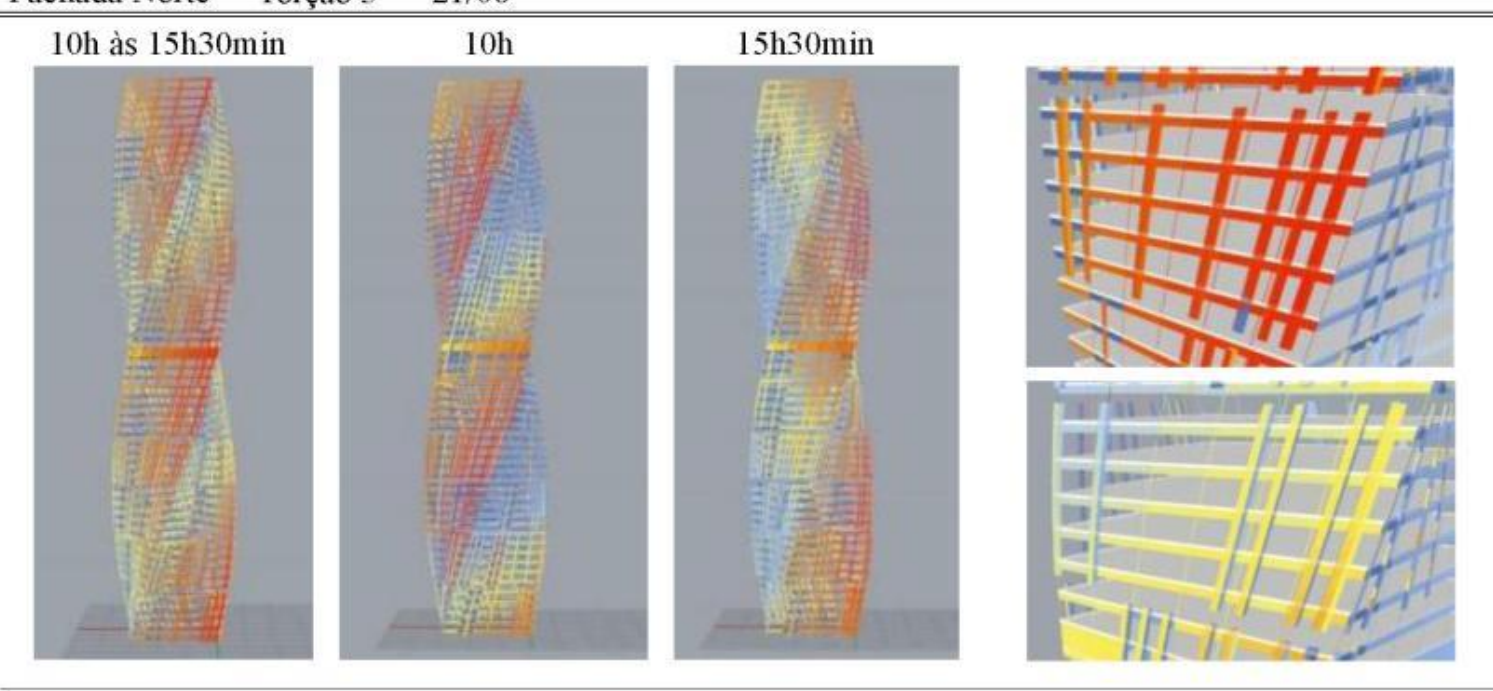

Legenda (em $\left.\mathrm{kWh} / \mathrm{m}^{2}\right)$

\begin{tabular}{|rrrrrrrrrrr}
\hline 0 & 0.35 & 0.70 & 1.05 & 1.40 & 1.75 & 2.10 & 2.45 & 2.80 & 3.15 & 0 \\
Fonte: Leone (2017).
\end{tabular}

\section{Experimento 4: proteção mista (vertical e horizontal)}

Devido ao fato de cada uma das orientações do edifício receber soluções distintas, com diferentes incidências da luz solar, a disponibilidade da iluminação natural no interior do ambiente resultou em uma distribuição não uniforme (Figura 15).

Baseado na análise do período crítico, foi possível identificar os momentos do dia no qual há maior incidência de radiação solar na fachada. Além disso, verificou-se que a fachada sul, em comparação às 
demais, é a que possui menor necessidade de proteção. Por outro lado, a fachada norte apresenta maior exposição à radiação solar durante maior extensão de tempo no momento crítico, seguida pela face oeste e posteriormente a leste. O estudo utilizando o algoritmo concebido para proteção mista - vertical e horizontal -, levou em consideração o momento crítico para adaptabilidade das variáveis criadas. Conforme demonstra a Figura 16, foram utilizadas soluções distintas nas diferentes fachadas, e, dessa maneira, é possível notar a incidência da radiação solar nas proteções, e não na superfície envidraçada do edifício.

Figura 15 - Iluminação natural com proteção vertical e horizontal às $10 \mathrm{~h}$ e $15 \mathrm{~h} 30$

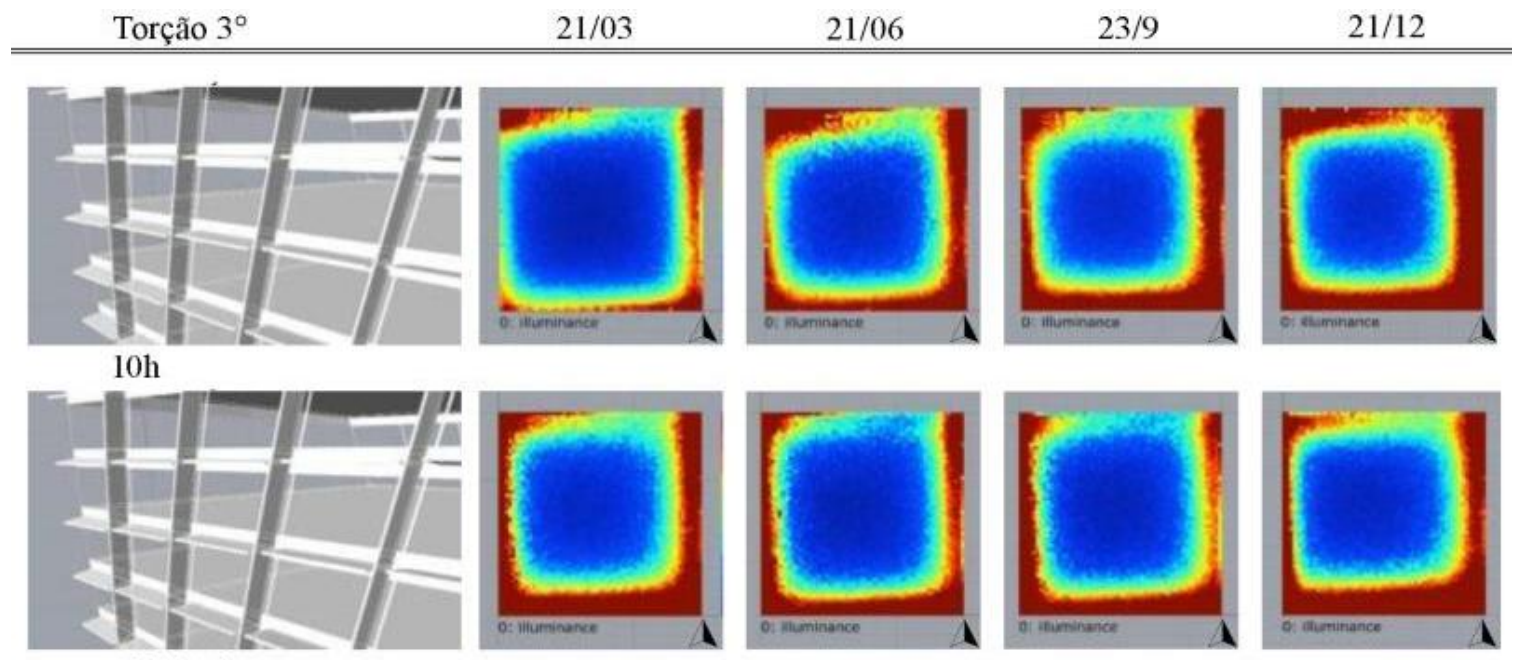

$15 \mathrm{~h} 30 \mathrm{~min}$.

Legenda (em Lux)

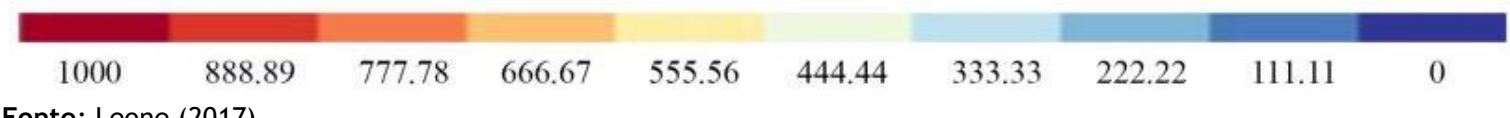

Fonte: Leone (2017).

Figura 16 - Radiação solar em edifício com proteção vertical e horizontal às $10 \mathrm{~h}$ e $15 \mathrm{~h} 30$ Torção $3^{\circ} \quad 21 / 06$

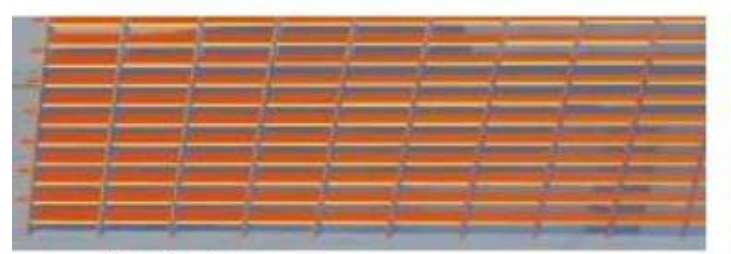

Norte $10 \mathrm{~h}$

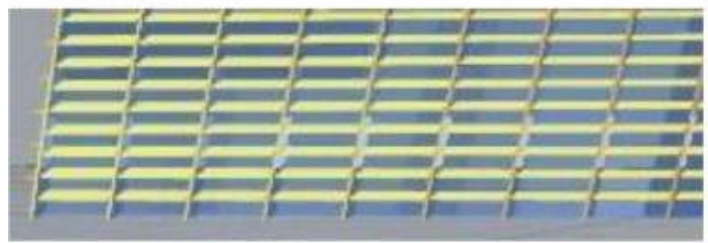

Norte $15 \mathrm{~h} 30 \mathrm{~min}$

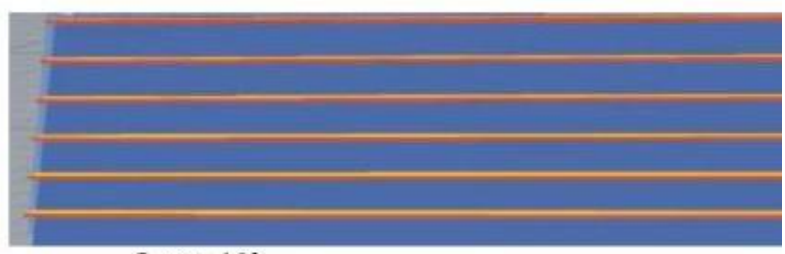

Leste $10 \mathrm{~h}$

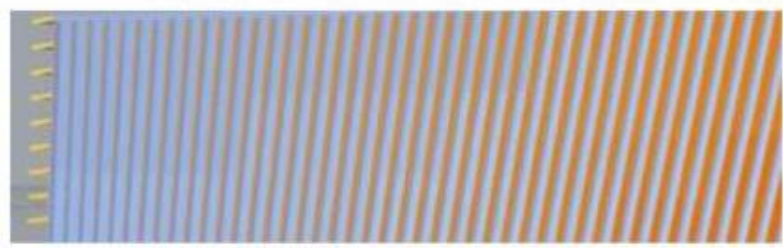

Oeste $15 \mathrm{~h} 30 \mathrm{~min}$

Legenda $\left(\mathrm{em} \mathrm{kWh} / \mathrm{m}^{2}\right)$

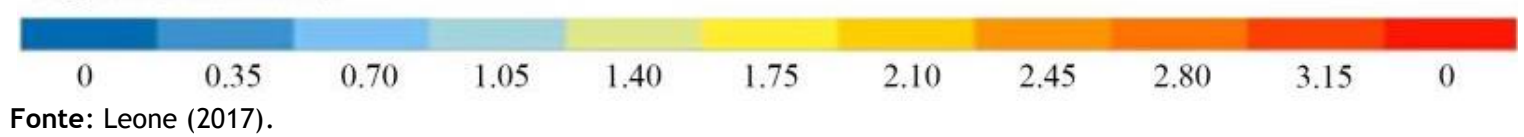


Ainda que os resultados pareçam óbvios quanto à necessidade de proteção solar nas orientações do edifício, utilizar simulações se dá justamente por tratar-se de um experimento com geometria torcida. Dessa maneira a solução com proteção torna-se singular, adequada à necessidade específica do pavimento ou trecho do edifício no qual faz sentido a proposta de projeto adotada.

Com a simulação é possível entender melhor qual o comportamento da incidência da radiação sobre o edifício, enquanto a utilização de geometrias para proteções solares parametrizadas favorece a busca pela melhor solução.

\section{Experimento 5: proteção com painéis}

No algoritmo do experimento 5, foram utilizados painéis de vedação para proteção solar. Como esperado, os resultados da simulação de iluminação natural no interior do ambiente demonstraram menor índice de iluminação natural nos locais em que os painéis são instalados (Figura 17). No entanto, a confiabilidade no projeto está justamente em saber que os elementos de proteção estão sendo utilizados em locais adequados, contribuindo para minimizar os ganhos de calor internos, resultando em maior conforto aos usuários.

Novamente, o experimento consiste na demonstração do método, no qual os resultados devem ser testados e reavaliados de acordo com a necessidade, a fim de encontrar a melhor solução possível. Por conseguinte, para distribuição dos elementos na fachada foi priorizada sua concentração nos locais mais críticos devido à intensidade da radiação. Mais uma vez é importante destacar que a utilização de simulações paramétricas auxilia decisões mais bem embasadas (Figura 18).

\section{Experimento 6: desenho da fachada}

O critério utilizado no experimento 6 para a elaboração de uma solução de fachada customizada para necessidades particulares de cada parte da envoltória foi baseado nos resultados das simulações em relação à radiação solar. Nos locais em que estão concentrados elementos opacos, isto é, sem transparência, como esperado, a iluminação interna apresentou um potencial de menor alcance (Figura 19).

Assim, a proposta seguiu a estratégia de priorizar fechamentos nas áreas que recebem maior radiação solar no momento crítico de incidência da radiação solar e maior transparência nas áreas de menor incidência da radiação. Os locais de maior concentração de $\mathrm{Kwh} / \mathrm{m}$ possuem maior percentual de áreas opacas, e aqueles com menor concentração, maiores as áreas de transparências, e, portanto, otimizando a iluminação natural (Figura 20).

Figura 17 - Iluminação natural com proteção tipo painel às $10 \mathrm{~h}$ e $15 \mathrm{~h} 30$

$\begin{array}{lllll}\text { Torção } 3^{\circ} & 21 / 03 & 21 / 06 & 23 / 9 & 21 / 12\end{array}$
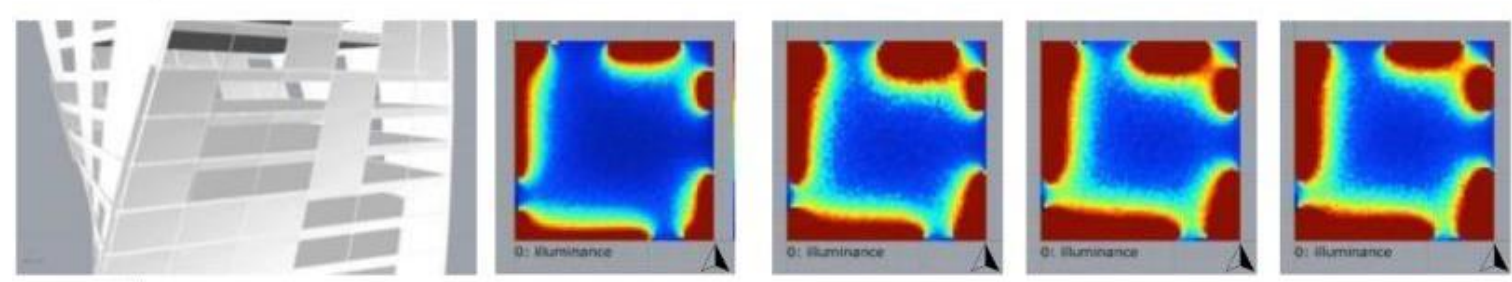

$10 \mathrm{~h}$
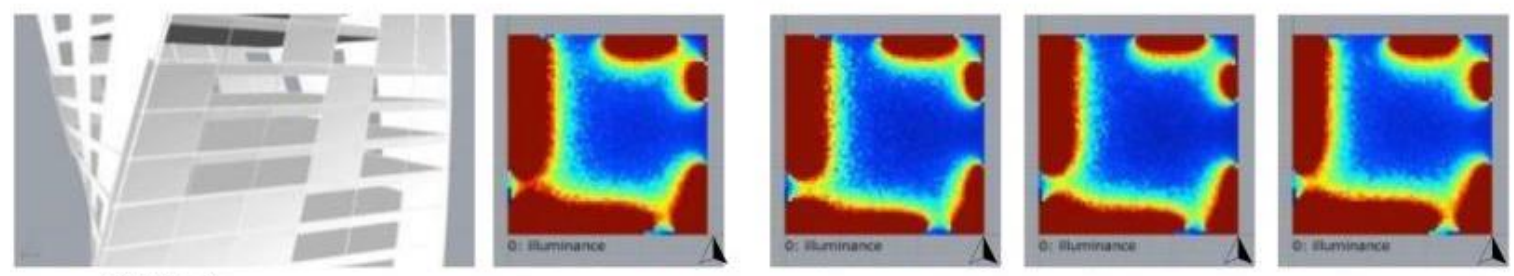

$15 \mathrm{~h} 30 \mathrm{~min}$

Legenda (em Lux)

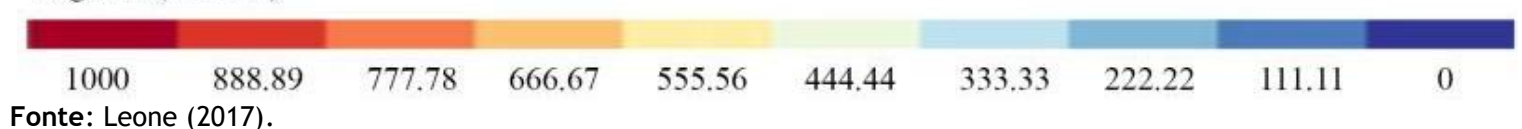

Fonte: Leone (2017). 
Figura 18 - Radiação solar em edifício com proteção tipo painel às $10 \mathrm{~h}$ e $15 \mathrm{~h} 30$

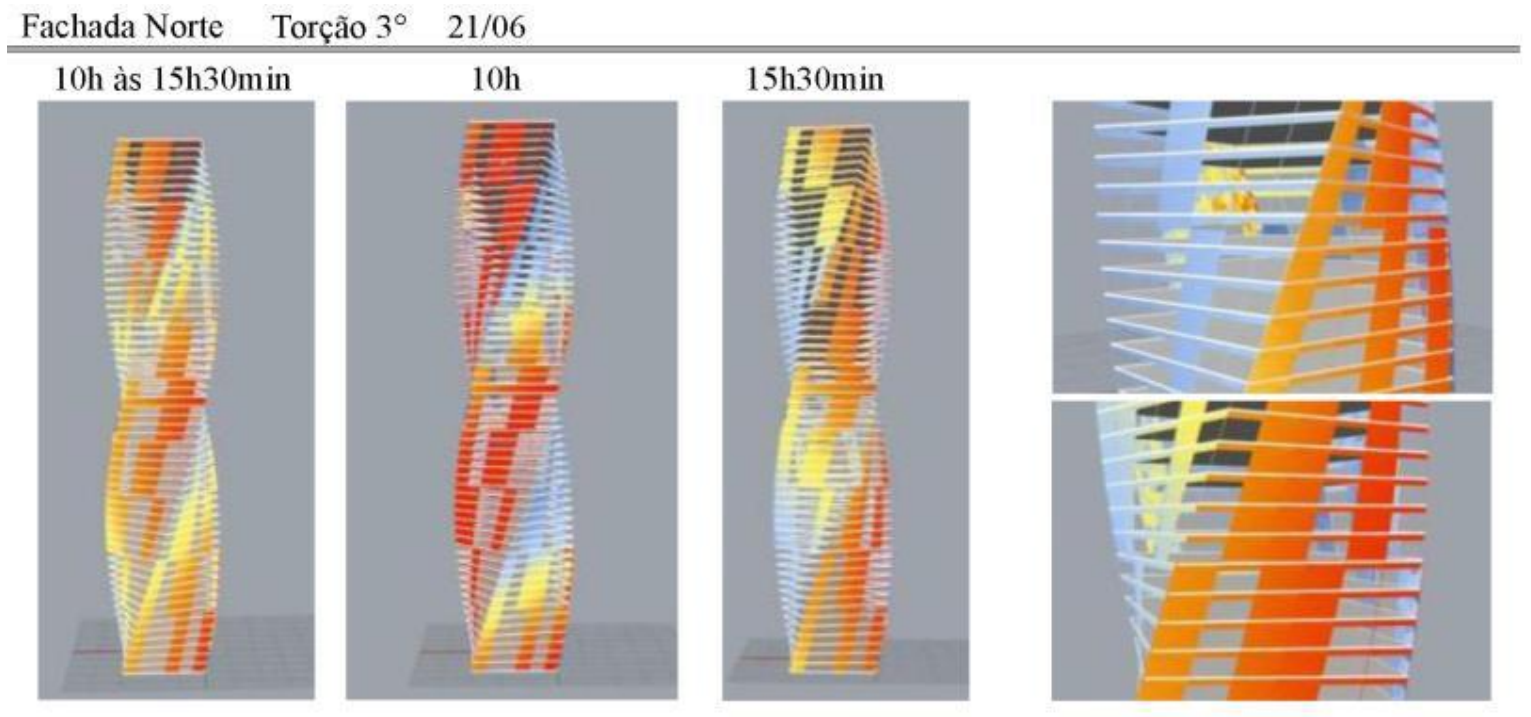

Legenda $\left(\mathrm{em} \mathrm{kWh} / \mathrm{m}^{2}\right)$

\begin{tabular}{lllllllllll}
\hline 0 & 0.35 & 0.70 & 1.05 & 1.40 & 1.75 & 2.10 & 2.45 & 2.80 & 3.15 & 3.50
\end{tabular}

Fonte: Leone (2017).

Figura 19 - Iluminação natural em edifício com variação do desenho da fachada às $10 \mathrm{~h}$ e $15 \mathrm{~h} 30$

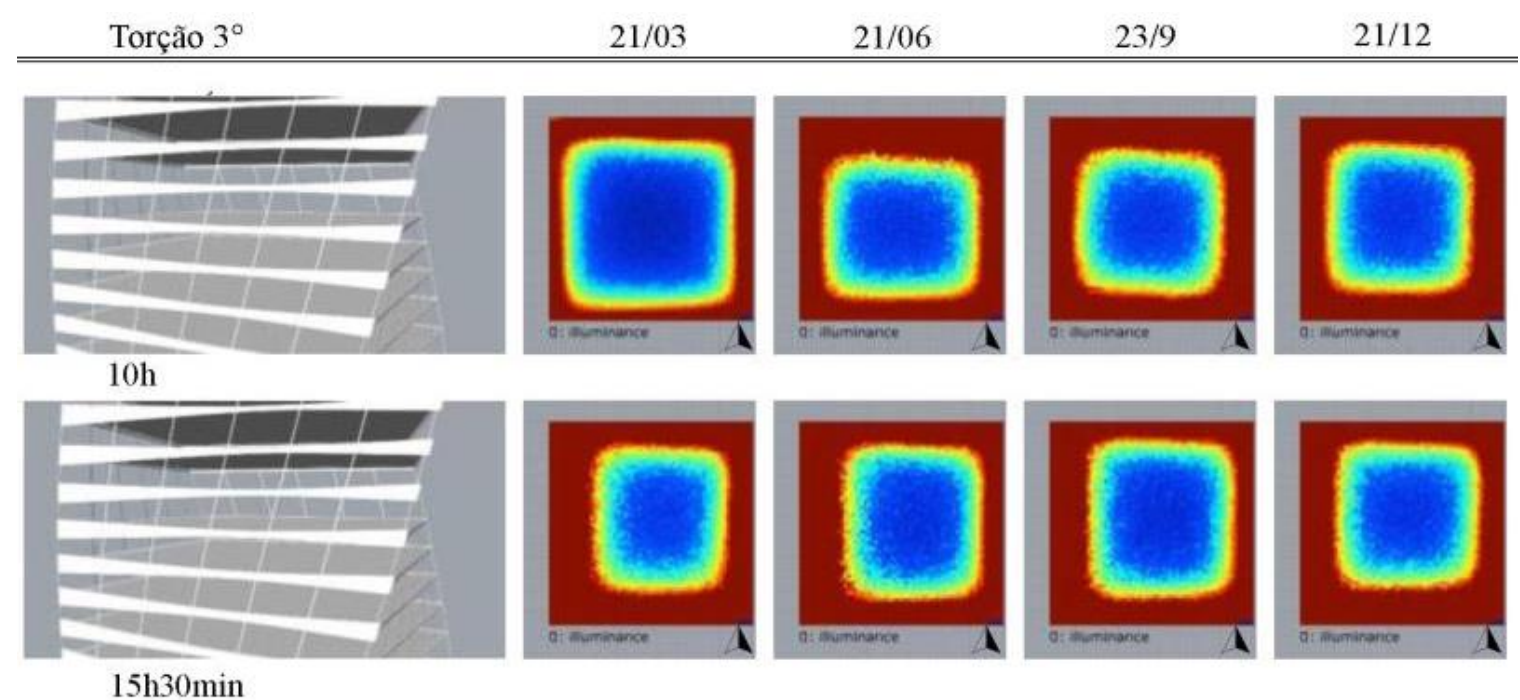

Legenda (em Lux)

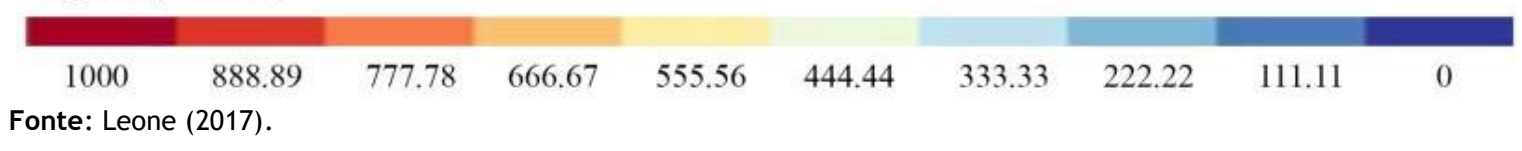


Figura 20 - Radiação solar em edifício com variação do desenho da fachada às $10 \mathrm{~h}$ e $15 \mathrm{~h} 30$

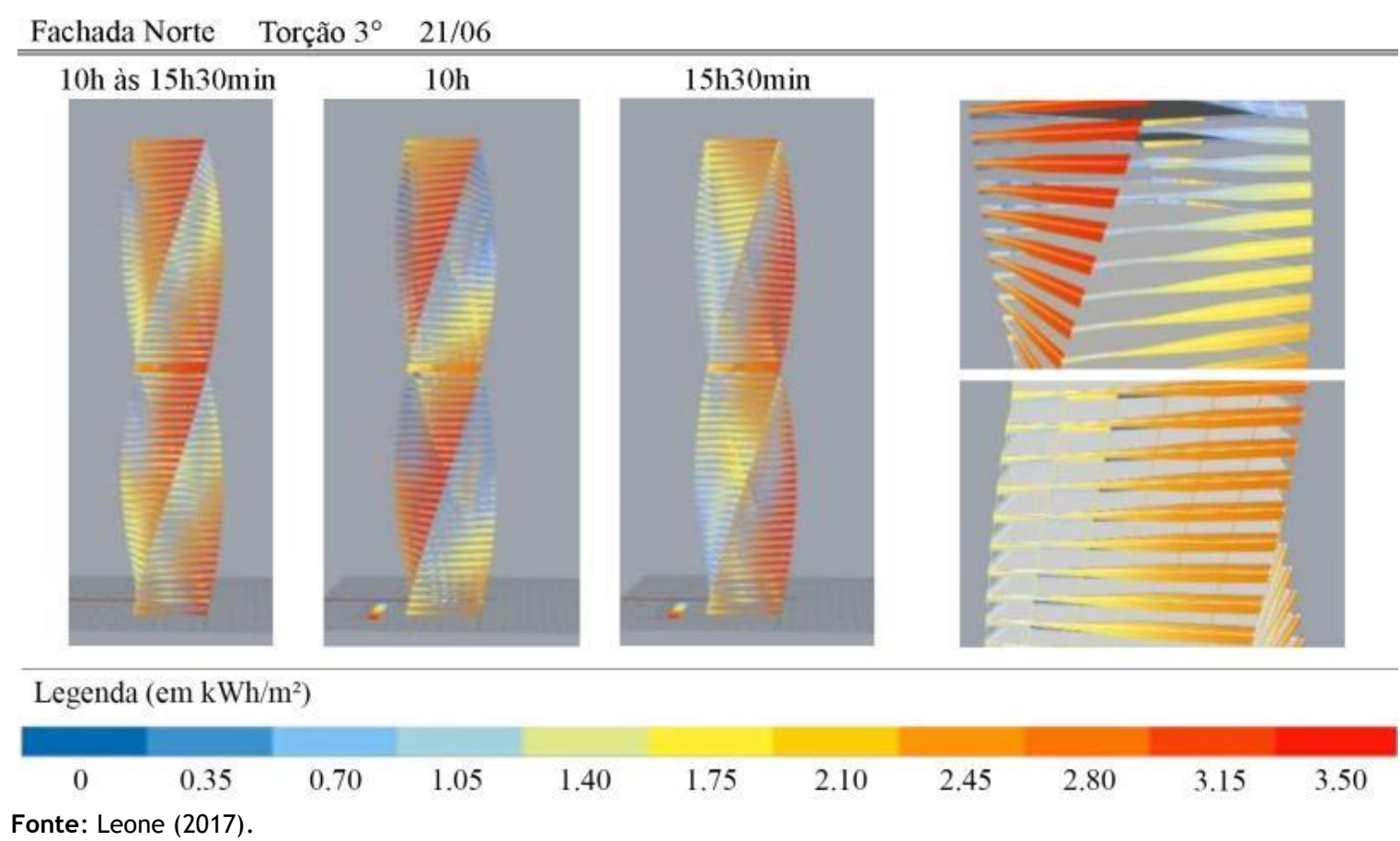

\section{Discussão}

Com base nos resultados dos seis experimentos, é possível afirmar que a MP, empregando o conceito de projeto baseado em desempenho (performance-based design), propicia a geração de alternativas de projeto, com avaliação comparativa dos resultados, propiciando o surgimento de soluções inesperadas decorrente das combinações entre os parâmetros inseridos no algoritmo. Além de gerar novas formas e explorar soluções singulares de projeto, a MP propicia decisões mais bem fundamentadas por fatos decorrentes das simulações.

A utilização da MP possibilita a criação de geometrias de edifícios adaptáveis a diversos contextos, permitindo a concepção de geometrias complexas, decorrente da combinação de parâmetros. Como as fachadas de edifícios não ortogonais são geometricamente únicas, admitem soluções particularizadas devido às necessidades específicas de cada pavimento. Consequentemente, a criação e o desenvolvimento paramétrico das aberturas e das proteções solares para sombreamento podem melhor atender a essas singularidades geométricas de edifícios torcidos.

De certa maneira as características de insolação nas orientações do edifício podem ser verificadas na carta solar. Contudo, devido ao edifício torcido apresentar particularidades, a simulação computacional colabora para a estratégia projetual no processo de projeto.

Diferente do edifício retilíneo, o edifício torcido não apresenta uniformidade da incidência da radiação solar nas fachadas. Nesse sentido, identificar quais locais possuem necessidade de proteção requer o emprego das tecnologias digitais.

Os algoritmos desenvolvidos para proteção solar no edifício modelo demonstraram soluções plausíveis para cada uma das proteções. Nos algoritmos criados, as variações dos parâmetros assemelham-se às características de proteções móveis, permitindo movimentação das lâminas, de acordo com a necessidade e trajetória solar.

A pesquisa se propôs a demostrar que a solução mais adequada é consequência de um processo que envolve diversas simulações, cujos resultados devem ser constantemente reavaliados. O processo paramétrico consiste em realizar alterações dos parâmetros do algoritmo, a fim de buscar resultados com maior concentração de elementos de proteção nos locais em que haja maior incidência da radiação. E, dessa maneira, o processo deve ser repetido até alcançar o resultado desejado. 
Nota-se que as avaliações propostas fazem parte de um processo contínuo, no qual são realizadas as simulações, análises dos resultados, reavaliação da geometria do elemento estudado, verificadas correções, alterações, novas avaliações e, por fim, a decisão, visando identificar os resultados de maior eficiência.

Com as simulações paramétricas foi possível avaliar a incidência da radiação solar na fachada do edifício e o comportamento da iluminação natural no interior do ambiente. Os resultados apontaram que a torção não favorece a iluminação natural no ambiente interno, sendo a geometria retilínea a configuração com melhor desempenho, para todas as configurações de janelas simuladas.

Por outro lado, no edifício com geometria torcida, a própria geometria complexa colabora para o autossombreamento da envoltória, tornando menor a necessidade de instalação de proteções solares em toda a extensão do edifício. No entanto, a radiação solar direta, incidente nos ângulos em que a fachada fica mais exposta, é maior se comparada à envoltória retilínea.

Na torção de $3^{\circ}$ (quando comparada a de $6^{\circ}$ ), a envoltória fica mais exposta aos raios solares, sendo viável a exploração de proteções solares para minimizar os ganhos de calor internos ao ambiente. No entanto, na torção de $6^{\circ}$, devido à inclinação da envoltória, alguns locais ficam mais expostos aos raios solares. Nesses casos as simulações demonstraram valores maiores quanto aos índices de calor na fachada. Em compensação, outros locais ficam protegidos, devido ao sombreamento causado pela própria curvatura da edificação, resultando em menor incidência da radiação solar na fachada. Consequentemente, há menor acúmulo de calor na superfície do material e menor massa térmica transmitida ao interior do ambiente. Assim, áreas sombreadas pela própria curvatura poderiam ser exploradas com a utilização de maiores aberturas na fachada, otimizando a iluminação natural.

Constatou-se que a geometria torcida apresenta melhores resultados quanto à incidência da radiação solar, ou seja, menor incidência, quando comparada com o desempenho de uma fachada totalmente plana.

Pudemos aferir que os procedimentos adotados fomentam as decisões no projeto, como o dimensionamento e posicionamento das aberturas, geometria do edifício, localização e necessidade de proteções solares, entre outros.

Se por um lado maiores aberturas na envoltória propiciam maior disponibilidade de luz natural, por outro há também maior incidência de radiação solar, que representa ganhos de calor no interior do edifício. No entanto, a solução adequada é aquela na qual há o equilíbrio entre as necessidades luminosas e térmicas.

A pesquisa colabora no estudo de estratégias que otimizam a energia passiva em projetos, alcançando economia de energia (eficiência energética) e viabilizando o conforto térmico e aproveitamento da iluminação natural. Isso se deu com a inserção de tecnologias digitais no estudo de geometrias únicas no projeto.

Acredita-se que a exploração da modelagem e simulação paramétrica se mostra como uma estratégia projetual colaborativa. Assim, a pesquisa se insere em um conjunto de estudos que buscam conceber a forma arquitetônica aliada à performance, correlacionando beleza ao desempenho técnico-funcional.

Diante desse quadro, a contribuição cientifica da presente pesquisa reside no estudo sobre a aplicação da modelagem e simulação paramétrica para a concepção de edifício de dupla curvatura, investigando estratégias projetuais que valorizem o processo de projeto.

$\mathrm{O}$ uso de programas computacionais que colaboram na busca pela forma (form-fiding), e na melhoria da performance, propicia uma arquitetura mais humana e com maior conforto. Portanto, pode-se afirmar que esses recursos paramétricos contribuem para a melhoria do ambiente construído, minimizando os impactos provocados pelos novos edifícios ao meio ambiente, por meio de soluções que resultem em maior eficiência energética.

\section{Considerações finais}

Neste artigo foi apresentado um conjunto de procedimentos baseados em algoritmos para concepção e análise do comportamento da iluminação natural no interior de edifícios torcidos. A pesquisa limitou-se a investigar uma pequena parcela de um processo de projeto muito mais complexo. Serão necessárias muitas pesquisas sobre o assunto tratado no presente artigo. Contudo, o artigo se propôs a debater a fundamental importância do uso de algoritmos na concepção de edifícios complexos, com geometrias e soluções únicas. O impacto educacional gerado pelo uso de tecnologias digitais na concepção arquitetônica será cada vez maior, particularmente nos cursos de graduação, que certamente deverão adequar-se às novas realidades. 
Nesse processo paramétrico, os arquitetos cada vez mais têm se apropriado de ferramentas digitais para conceber, simular e analisar edifícios, de modo a tornar mais consciente a escolha da alternativa mais adequada a cada situação de projeto. A utilização cada vez maior de algoritmos altera o modo de projetar. Diante disso, é evidente o impacto organizacional que reflete a mudança no ofício da arquitetura.

Outras pesquisas deverão ser realizadas para avaliar o impacto das novas tecnologias no ofício da profissão e no âmbito educacional, assim como pesquisas futuras quanto ao conforto acústico, visual, ventilação, entre outras, em busca da solução adequada. Assim, abrem-se boas perspectivas para trabalhos futuros que proponham o aprimoramento dos algoritmos a fim de alcançar uma arquitetura mais humana.

\section{Referências}

ABDULLAH, H. K.; ALIBABA, H. Z. Retrofits for energy eficiente office buildings: integration of optimized photovoltaics in the form of responsive shading devices. Sustainability, v. 9, n. 11, 2017.

ASSOCIAÇÃO BRASILEIRA DE NORMAS TÉCNICAS. NBR 15215-1: iluminação natural. Rio de Janeiro, 2005b.

ASSOCIAÇÃO BRASILEIRA DE NORMAS TÉCNICAS. NBR 15220-1: desempenho térmico de edificações. Rio de Janeiro, 2005a.

ASSOCIAÇÃO BRASILEIRA DE NORMAS TÉCNICAS. NBR 15575-1: edifícios habitacionais: desempenho: parte 1: requisitos gerais. Rio de Janeiro, 2013b.

ASSOCIAÇÃO BRASILEIRA DE NORMAS TÉCNICAS. NBR 8995-1: Iluminação de ambientes de trabalho. Rio de Janeiro, 2013a.

BURRY, M. Homo Faber. Architectural Design, v. 75, n. 4, p. 30-37, 2005.

CARPO, M. The alphabet and the algorithm. Cambridge: MIT Press, 2011.

CECCATO, C. Material articulation: computing and constructing continuous differentiation. Architectural Design, v. 82, n. 2, p. 96-103, 2012.

COTTA, J.; VIEIRA, J. L. O desempenho térmico de ambientes de trabalho nas cidades de São Paulo e Rio de Janeiro. In: GONÇALVES, J. C. S; BODE, K. Edifício ambiental. São Paulo: Oficina de textos, 2015.

DUARTE, D. O clima urbano e o ambiente construído. In: GONÇALVES, J. C. S; BODE, K. Edifício ambiental. São Paulo: Oficina de textos, 2015.

ELTAWEEL, A.; SU, Y. Using integrated parametric control to achieve better daylighting uniformity in na office room: a multi-step comparison study. Nottingham: Department of Architecture and Build Environment, University of Nottingham, 2017.

EMMANUEL, M. R. A hipothetical "shadow umbrella" for thermal comfort enhancement in the equatorial urban outdoors. Architectural Science Review, v. 36, n. 4, p. 173-184, 1993.

ERCAN, B.; ELIAS-OZAKAN, S. T. Performance-based parametric design explorations: a method for generating appropriate building componentes. Ankara: Middle East Technical University, 2015.

FONSECA, R. W. da; PEREIRA, F. O. R.; CLARO, A. Iluminação natural: a contribuição de suas reflexões no interior do ambiente construído. Pós. Revista do Programa de Pós-Graduação em Arquitetura e Urbanismo da FAUUSP, v. 17, p. 198-217, 2010.

FROTA, A. B. Geometria da insolação. São Paulo: Geros, 2004.

FROTA, A. B.; SCHIFFER, S. R. Manual de conforto térmico: arquitetura, urbanismo. 5. ed. São Paulo: Studio Nobel, 2001.

GONÇALVES, J. C. S.; MOURA, N. C. S.; KUNIOCHI, E. M. U. Avaliação de desempenho, simulação computacional e o projeto arquitetônico. In: GONÇALVES, J. C. S; BODE, K. Edifício ambiental. São Paulo: Oficina de textos, 2015.

GONÇALVES, J. C.; BAKER N. A reabilitação de edifícios. In: GONÇALVES, J. C. S; BODE, K. Edifício ambiental. São Paulo: Oficina de textos, 2015.

HOPKINSON, R. Architectural physics: lighting. London: Her Majesty's Stationery Office, 1963. 
HUDSON, R.; SHEPHERD, P.; HINES, D. Aviva Stadium: a case study in integrated parametric design. International Journal of Architectural Computing, v. 9, n. 2, p. 187-203, 2011.

JALALI, Z., NOORZAI, E.; HEIDARI, S. Design and optimization of form and facade of an office building using the genetic algorithm. Science and Technology for the Built Environment, v. 26, n. 2, p. 128-140, 2019.

KOLAREVIC, B. Architecture in the digital age: design and manufacturing. New York: Spon Press, 2003.

LABORATÓRIO DE CONFORTO AMBIENTAL. Bloco 2 - Iluminação. Aula 2 - Iluminação Natural. Santa Catarina, 2009. Disponível em: http://www.ufrgs.br/labcon2/Aula\%202\%20$\% 20 I l u m i n a \% \mathrm{C} 3 \% \mathrm{~A} 7 \% \mathrm{C} 3 \% \mathrm{~A} 30 \% 20$ Natural.pdf Acesso em: agosto 2016.

LEONE, C. Modelagem paramétrica: concepção de torres torcidas e proteções solares para análise de iluminação natural e radiação solar em edifício comercial na cidade de São Paulo. São Paulo, 2017. Dissertação (Mestrado em Arquitetura e Urbanismo) - Universidade Presbiteriana Mackenzie, São Paulo, 2017.

LYNCH, P. How energy modeling will impact the design process. Archdaily, 8 de dezembro de 2015. Disponível em: https:/www.archdaily.com/778309/how-energy-modeling-will-impact-the-design-process. Acesso em: 6 abr. 2016.

MARCONDES, M. P. Soluções projetuais de fachada para edifícios de escritórios com ventilação natural em São Paulo. São Paulo, 2010. Tese (Doutorado em Arquitetura e Urbanismo) - Universidade de São Paulo, São Paulo, 2010.

MASCARÓ, L. R. de. Energia na edificação: estratégia para minimizar seu consumo. São Paulo: Projeto Editores, 1991.

MILLER, N. The Hangzhou Tennis Center: a case study in parametric design. In: PARAMETRICISM (SPC) ACADIA REGIONAL 2011 CONFERENCE PROCEEDINGS, Nebraska, 2011. Proceedings [...] Nebraska: University of Nebraska, 2011.

PICON, A. Digital culture in architecture. Boston: Birkhaeuser, 2010.

RORIZ, M. Arquivos Climáticos de Municípios Brasileiros. Associação Nacional de Tecnologia do Ambiente Construído. Grupo de Trabalho sobre Conforto e Eficiência Energética de Edificações. São Carlos, 2012. Disponível em: http://roriz.dominiotemporario.com/doc/Sobre_os_arquivos_EPW.pdf. Acesso em: 5 mar. 2015.

SANCHES, T. B.; AMORIM, A. L. Avaliação do uso da simulação computacional em projetos de iluminação artificial. In: IBEROAMERICAN CONGRESS OF DIGITAL GRAPHICS, 5., Chile, 2001. Proceeding [...] Chile: BioBio, 2001.

SCHEURER, F. Materialising complexity. Architectural Design, v. 80, n. 4, p. 86-93, 2010.

SCHODEK, D. et al. Digital design and manufacturing CAD/CAM applications in architecture and design. Longon: John Wiley \& Sons, 2004.

SCHUMACHER, P. Parametricism: a new global style for architecture and urban desing. Architectural Design, v. 79, n. 4, p. 14-23, 2009.

TABLADA, A. et al. Design optimization of productive façades: integrating photovoltaic and farming systems at the tropical technologies laboratory. Sustainability, v. 10, 2018.

VOLLERS, K. Twist \& Build: creating non-orthogonal architecture. Rotterdam: 010 Publishers, 2001. 


\section{Camila Leone}

Faculdade de Arquitetura e Urbanismo | Universidade Presbiteriana Mackenzie | Rua da Consolação, 930, Higienópolis | São Paulo - SP Brasil | CEP 01302-907 | Tel.: (11) 99421-1008 | E-mail: camilaleone.arq@gmail.com

\section{Wilson Florio}

Faculdade de Arquitetura e Urbanismo | Universidade Presbiteriana Mackenzie | Tel.: (11) 94477-9381 | E-mail: wilsonflorio@gmail.com

\section{Ambiente Construído}

Revista da Associação Nacional de Tecnologia do Ambiente Construído

Av. Osvaldo Aranha, $99-3^{\circ}$ andar, Centro

Porto Alegre - RS - Brasil

$$
\text { CEP } 90035-190
$$

Telefone: +55 (51) 3308-4084

www.seer.ufrgs.br/ambienteconstruido

$$
\text { www.scielo.br/ac }
$$

E-mail: ambienteconstruido@ufrgs.br

(c) ()

270 Leone, C.; Florio, W. 